\title{
Testosterone Depletion in Adult Male Rats Increases Mossy Fiber Transmission, LTP, and Sprouting in Area CA3 of Hippocampus
}

\author{
Vanessa A. Skucas, ${ }^{1}$ Aine M. Duffy, ${ }^{1}$ Lauren C. Harte-Hargrove, ${ }^{1}$ Alejandra Magagna-Poveda, ${ }^{2}$ Thomas Radman, ${ }^{3}$ \\ Goutam Chakraborty, ${ }^{1}$ Charles E. Schroeder, ${ }^{1,4}$ Neil J. MacLusky, ${ }^{5}$ and Helen E. Scharfman ${ }^{1,6}$ \\ ${ }^{1}$ Nathan Kline Institute for Psychiatric Research, Center of Dementia Research, Orangeburg, New York 10962, ${ }^{2}$ Cantonal Hospital of Basel-Land, Institute of \\ Pathology, 4410 Basel-Land, Switzerland, ${ }^{3}$ BrainScope, Bethesda, Maryland 20912, ${ }^{4}$ Department of Psychiatry, Columbia University, New York, New York \\ 10032, ${ }^{5}$ University of Guelph, Department of Biomedical Science, Ontario Veterinary College, Guelph, Ontario N1G 2W1, Canada, and ${ }^{\circ}$ New York University \\ Langone Medical Center, Departments of Child \& Adolescent Psychiatry, Physiology \& Neuroscience, and Psychiatry, New York, New York 10016
}

Androgens have dramatic effects on neuronal structure and function in hippocampus. However, androgen depletion does not always lead to hippocampal impairment. To address this apparent paradox, we evaluated the hippocampus of adult male rats after gonadectomy $(\mathrm{Gdx})$ or sham surgery. Surprisingly, Gdx rats showed increased synaptic transmission and long-term potentiation of the mossy fiber (MF) pathway. Gdx rats also exhibited increased excitability and MF sprouting. We then addressed the possible underlying mechanisms and found that Gdx induced a long-lasting upregulation of MF BDNF immunoreactivity. Antagonism of Trk receptors, which bind neurotrophins, such as BDNF, reversed the increase in MF transmission, excitability, and long-term potentiation in Gdx rats, but there were no effects of Trk antagonism in sham controls. To determine which androgens were responsible, the effects of testosterone metabolites DHT and $5 \alpha$-androstane- $3 \alpha, 17 \beta$-diol were examined. Exposure of slices to $50 \mathrm{~nm}$ DHT decreased the effects of Gdx on MF transmission, but 50 nм $5 \alpha$-androstane- $3 \alpha, 17 \beta$-diol had no effect. Remarkably, there was no effect of DHT in control males. The data suggest that a Trk- and androgen receptor-sensitive form of MF transmission and synaptic plasticity emerges after Gdx. We suggest that androgens may normally be important in area CA3 to prevent hyperexcitability and aberrant axon outgrowth but limit MF synaptic transmission and some forms of plasticity. The results also suggest a potential explanation for the maintenance of hippocampal-dependent cognitive function after androgen depletion: a reduction in androgens may lead to compensatory upregulation of MF transmission and plasticity.

\section{Introduction}

Although the effects of estrogens on the hippocampus have been studied extensively (Spencer et al., 2008; Smith et al., 2009; Barha and Galea, 2010; Foy, 2010; Wojtowicz and Mozrzymas, 2010; Fester et al., 2011), how androgens affect the hippocampus remains poorly understood. Androgen receptors are abundant in the hippocampus (Clancy et al., 1992; Brown et al., 1995; Kerr et al., 1995; DonCarlos et al., 2003; Tabori et al., 2005; Sarkey et al., 2008), suggesting that androgens regulate hippocampal function. Moreover, there are many examples of sex differences in hippocampus (for review, see McEwen and Milner, 2007; Galea, 2008; McLaughlin et al., 2009; Mitsushima, 2011), which also

Received Aug. 8, 2012; revised Dec. 8, 2012; accepted Dec. 10, 2012.

Author contributions: H.E.S. and N.J.M. designed research; V.A.S., A.M.D., L.C.H.-H., A.M.-P., G.C., and H.E.S. performed research; T.R. contributed unpublished reagents/analytic tools; V.A.S., A.M.D., L.C.H.-H., A.M.-P., G.C., T.R., C.E.S., N.J.M., and H.E.S. analyzed data; C.E.S., N.J.M., and H.E.S. wrote the paper.

This work was supported by NIH Grants R01 NS 37562 and T32 MH 097763. We thank Teresa A. Milner for the antibody to dynorphin and Joseph P. Pierce for discussion.

The authors declare no competing financial interests.

Correspondence should be addressed to Dr. Helen E. Scharfman, Nathan Kline Institute for Psychiatric Research, Center of Dementia Research, 140 Old Orangeburg Road, Building 35, Orangeburg, NY 10962. E-mail: hscharfman@nki.rfmh.org or helen.scharfman@nyumc.org.

DOI:10.1523/JNEUROSCI.3857-12.2013

Copyright $\odot 2013$ the authors $\quad 0270-6474 / 13 / 332338-18 \$ 15.00 / 0$ suggest a role of androgens (Becker et al., 2008; Etgen and Pfaff, 2009; Mitsushima et al., 2009). Studies examining the effects of androgens in hippocampus have, however, yielded mixed results. In rodents, testosterone administration improves hippocampaldependent behavior in some studies (Edinger and Frye, 2004; Edinger and Frye, 2007a,b; Frye et al., 2008) but not others (Naghdi and Asadollahi, 2004; Naghdi et al., 2005; Harooni et al., 2008). Testosterone application to hippocampal slices of adult male rats potentiates Schaffer collateral transmission in area CA1 (Smith et al., 2002), but testosterone depletion after gonadectomy (Gdx) can facilitate long-term potentiation (LTP) in area CA1 (Harley et al., 2000; Sakata et al., 2000). Testosterone administration to Gdx rats increases the number of spine synapses in stratum radiatum of area CA1 (Leranth et al., 2003), consistent with a role for androgen in maintaining normal cognitive function (MacLusky et al., 2006). However, in men, androgen ablation therapy for prostate cancer leads to few or no significant deficits in cognitive performance (Nelson et al., 2008; Alibhai et al., 2010a,b; Matousek and Sherwin, 2010). The reduced levels of androgens in aging men are often considered to be a contributing factor to diseases that increase with age, such as Alzheimer's disease (Fuller et al., 2007; Drummond et al., 2009; Barron and Pike, 2011; Luchetti et al., 2011), epilepsy (Herzog, 1991; Harden and 
MacLusky, 2004, 2005; Frye, 2006; Reddy, 2010; Stevens and Harden, 2011), and Parkinson's disease (Al Sweidi et al., 2011). However, direct evidence in support of this idea, such as prevention of these diseases by androgen therapy, is generally weak, although androgens ameliorate symptoms in some instances (Herzog, 1991; Almeida and Flicker, 2003; Cherrier et al., 2005; Harden and MacLusky, 2005; Driscoll and Resnick, 2007).

We hypothesized that the actions of testosterone on the hippocampus might involve both positive and negative effects, which could explain previous contradictory results. This idea originated in our findings that intact male rats exhibit low levels of hippocampal BDNF immunoreactivity compared with females, primarily in the mossy fiber (MF) pathway (Scharfman et al., 2003). Therefore, androgens may normally keep BDNF protein levels relatively low, which would maintain normal excitability but possibly limit plasticity (i.e., androgens would have positive and negative effects). In addition, this hypothesis is based on previous studies suggesting an important role for neurotrophins as mediators of gonadal steroid action (Toran-Allerand, 1992; Toran-Allerand et al., 1996) and specifically androgens and BDNF, in avian or neuromuscular systems (Louissaint et al., 2002; Ball et al., 2004; Ottem et al., 2007; Wissman and Brenowitz, 2009; Verhovshek et al., 2010). Therefore, we asked whether testosterone regulates $\mathrm{BDNF}$ expression in MFs, as well as anatomical and electrophysiological indices of MF transmission and plasticity in adult male rats. Our results show, remarkably, that Gdx rats exhibit increased BDNF protein expression in the MFs and increased MF plasticity.

\section{Materials and Methods}

Adult male rats (Charles River) were bred in-house, weaned at 21-23 d, and housed ( 2 or $3 /$ cage) with food (Purina 5001, WF Fisher) and water ad libitum and a $12 \mathrm{~h}$ light:dark cycle. Chemicals were from SigmaAldrich unless stated otherwise. All procedures involving animals were approved by the animal care and use committee of the Nathan Kline Institute for Psychiatric Research.

\section{Surgical procedures}

Before Gdx, animals were anesthetized with $1 \mathrm{ml} / \mathrm{kg}$ ketamine-xylazine solution $(80 \mathrm{mg} / \mathrm{ml}$ ketamine hydrochloride and $12 \mathrm{mg} / \mathrm{ml}$ xylazine hydrochloride). Bilateral Gdx was conducted as previously described (Edwards et al., 1999). In brief, a half-inch midline incision of the lower abdomen was followed by removal of the testes and ligation around the vasculature adjacent to each gonad with sterile sutures (Dermalon, Henry Schein). The incision was closed with wound clips (Stoelting), swabbed with betadine (Henry Schein), and animals were placed over a heating pad (Homeothermic Blanket, Harvard Apparatus) until they recovered from anesthesia. Sham surgery used the same procedures, but the testes were not removed from the abdominal cavity.

For comparison of Gdx and sham rats in the Results section, animals were subjected to surgery shortly after puberty $(50-60 \mathrm{~d}$ old $)$. Animals were used for experiments $\sim 2$ weeks later to allow ample time for recovery.

\section{Electrophysiology}

Slice preparation

After deep anesthesia by isoflurane inhalation, the rat was decapitated, the brain was removed from the skull, and it was placed in ice-cold $\left(4^{\circ} \mathrm{C}\right)$ oxygenated $\left(95 \% \mathrm{O}_{2} / 5 \% \mathrm{CO}_{2}\right)$ sucrose-based artificial CSF (ACSF, in mu: 252.0 sucrose, $5.0 \mathrm{KCl}, 2.4 \mathrm{CaCl}_{2}, 2.0 \mathrm{MgSO}_{4}, 26.0 \mathrm{NaHCO}_{3}, 1.25$ $\mathrm{NaH}_{2} \mathrm{PO}_{4}, 10.0$ D-glucose) for $\sim 2 \mathrm{~min}$. One hemisphere was glued with cyanoacrylate (Krazy Glue) to the Teflon-coated stage of a vibrating tissue slicer (Vibroslice, Stoelting) and slices $(400-\mu \mathrm{m}$-thick) were cut in the horizontal plane while immersed in $4^{\circ} \mathrm{C}$ ACSF. Slices were placed immediately in $100 \mathrm{ml}$ of preoxygenated, room-temperature ACSF, and placed with a wide-bore Pasteur pipette on a nylon net of a recording chamber (modified from one previously sold by Fine Science Tools)
(Scharfman et al., 2001) to provide improved flow of ACSF and increased aeration (http://www.healthresearch.org/technology-transfer/brain-andtissue-slice-recording). Slices were perfused with oxygenated $\left(95 \% \mathrm{O}_{2} /\right.$ $\left.5 \% \mathrm{CO}_{2}\right)$, preheated $\left(30^{\circ} \mathrm{C}\right)$ ACSF at $\sim 1 \mathrm{ml} / \mathrm{min}$ by a peristaltic pump (Minpuls2 Gilson). The compartment of the recording chamber where slices were placed was maintained at $31-32^{\circ} \mathrm{C}$ by a temperature controller (PTCO3, Scientific Systems Design). After $30 \mathrm{~min}$, slices were perfused with $\mathrm{NaCl}$-based ACSF (126.0 mM NaCl instead of sucrose). Recordings began $60 \mathrm{~min}$ after slices were first placed in the recording chamber and 30 min after the start of perfusion with $\mathrm{NaCl}$-ACSF.

\section{Recording}

Similar recording procedures to those described previously (Scharfman et al., 2000, 2007; Skucas et al., 2011) were used. Recording electrodes were pulled (Model P87, Sutter Instruments) from borosilicate glass with a capillary in the lumen $(1.0 \mathrm{~mm}$ outer diameter, $0.75 \mathrm{~mm}$ inner diameter, World Precision Instruments). Recording electrodes were filled with $\mathrm{NaCl}-\mathrm{ACSF}$ and resistances were 3-6 M $\Omega$. Recordings were amplified (Axoclamp 2B, Molecular Devices), digitized (Digidata 1440A, Molecular Devices), and acquired using pClamp (Molecular Devices). For recording sites, a depth in the slice was chosen where the maximal response was elicited, typically $50-100 \mu \mathrm{m}$ below the surface. For laminar analysis, the exact depth was determined by a calibrated micromanipulator with precision to the nearest micron (Leica Microsystems) and was the same for all recording sites.

\section{Stimulation}

Monopolar stimulating electrodes were made from Teflon-coated stainless steel wire (diameter including Teflon, $75 \mu \mathrm{m}$; A-M Systems). Stimuli were controlled by a stimulus isolation unit (IsoFlex, AMPI Instruments) that generated current pulses $(100 \mu \mathrm{A})$, which were varied in duration digitally $(10-250 \mu \mathrm{s})$ to test different stimulus strengths. Stimuli were triggered every $30-40 \mathrm{~s}$ to test basal transmission.

For stimulation of MFs, recordings were in $\mathrm{CA} 3 \mathrm{~b}$ and the stimulating electrode was placed in the subgranular zone (SGZ) at the crest of the DG (Fig. 1) because this location avoided stimulation of CA3c pyramidal cell dendrites and activation of area CA3 recurrent collaterals to other CA3 pyramidal cells (Claiborne et al., 1993). The response to MF stimulation was recorded at many sites in stratum lucidum in CA3b at the onset of each experiment to determine the location within stratum lucidum where the maximal field EPSP (fEPSP) was recorded. Other methods to confirm that the SGZ stimulus activated MFs are shown in Figure 1. Nevertheless, we cannot exclude the possibility that a pathway in addition to the MF pathway was activated by SGZ stimulation (e.g., the backprojecting axons of CA3 pyramidal cells that extend deep into the hilus) (Scharfman, 2007).

\section{LTP}

LTP experiments required a stable baseline, which was defined by a 15 min period when the fEPSP slope varied within $95-105 \%$ of the mean of the first 3 evoked responses. For MF plasticity, a $25 \mathrm{~Hz}, 1 \mathrm{~s}$ train was triggered twice with a $10 \mathrm{~s}$ interval, and stimulus strength was $50 \%$ of the strength that elicited the maximum fEPSP. For $\theta$-burst stimulation (TBS), 10 trains of 4 half-maximal stimuli at $100 \mathrm{~Hz}$ were triggered 200 $\mathrm{ms}$ apart. fEPSPs were normalized to the average of the $15 \mathrm{~min}$ baseline.

\section{Data analysis}

fEPSP. Slope was defined as the slope between two points: the start of the fEPSP and the peak. When a fiber volley preceded an fEPSP, the first point of the fEPSP slope measurement was immediately after the fiber volley. This definition of slope was chosen because the fEPSPs in Gdx rats often had an irregular rising phase, making the maximal slope difficult to measure (see Fig. 9A2). fEPSP amplitude was defined as the difference between the prestimulus baseline and the peak of the fEPSP. Paired pulse facilitation (PPF) was defined as the measurement of the second response divided by the measurement of the first response. Latency was measured from the middle of the stimulus artifact, which was $10-285 \mu \mathrm{s}$ in duration, to the onset of the initial negative deflection representing the rising phase of the fiber volley (for latency to the fiber volley) or the onset of the rising phase of the fEPSP (for latency to fEPSPs) (Skucas et al., 2011). 
A

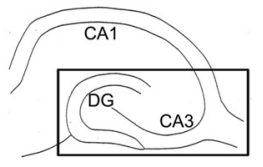

D1 Weak stimulus

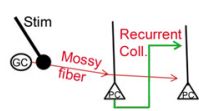

2

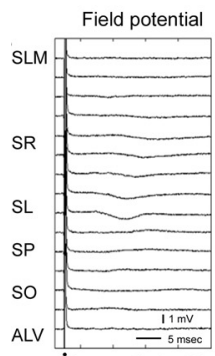

B

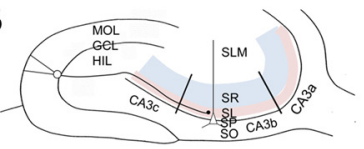

E1 strong stimulus

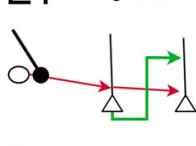

2

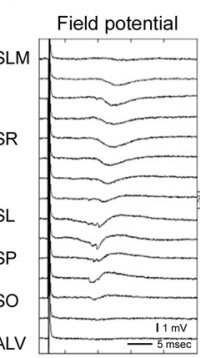

C

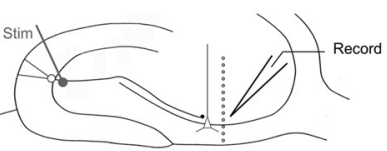

F1 Effect of DCG-IV

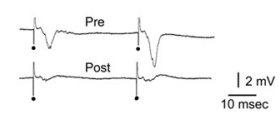

2

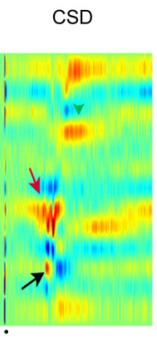

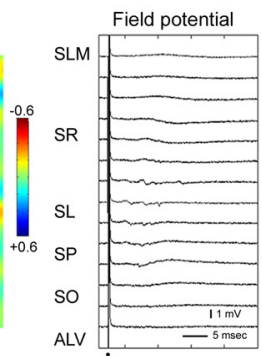

CSD

Figure 1. Methods to record MF fEPSPs. $A$, A diagram of the hippocampus in horizontal section. $B$, The area outlined by the box in $A$ is expanded to show the areas of the dentate gyrus and CA3 used in the experiments. SLM, Stratum lacunosum-moleculare; SR, stratum radiatum (light blue); $\mathrm{SL}$, stratum lucidum (light red); SP, stratum pyramidale; $\mathrm{SO}$, stratum oriens. CA3a- c are separated by lines reflecting divisions described previously (Lorento de No, 1934). The MF pathway is illustrated by a single granule cell and its main axon, terminating in stratum lucidum of area CA3. Granule cell MFs also collateralize in the hilus (HIL). GCL, Granule cell layer; MOL, molecular layer. C, An illustration of the recording and stimulation sites. The stimulation site (Stim) was the subgranular zone of the crest of the dentate gyrus. The recording site (Record) was in CA3b. For CSD analysis, recordings were made along an axis perpendicular to the cell layer (small circles indicate approximate recording sites). D1, Left, A schematic illustrates the circuitry underlying responses elicited by low intensities of stimulation. Red arrows indicate the MF pathway; and green arrows, the recurrent collateral pathway. Right, The red arrow shows that the predominant response to low-intensity stimulation is an fEPSP recorded in stratum lucidum. In this figure and all others, the dots mark the stimulus artifacts, which are truncated. D2, A CSD analysis for the same slice using responses recorded from the alveus to stratum lacunosum-moleculare. The primary current sink is in stratum lucidum (red arrow). This short-latency current sink was followed by a longer-latency sink in stratum radiatum (green arrowhead). Calibration: +0.6 to $-0.6 \mathrm{mV} / \mathrm{mm}^{2}$. E1, A schematic (on the left) illustrates the circuitry underlying the responses on the right, which were evoked with higher intensity of stimulation. The recurrent collateral pathway is activated more than in $\boldsymbol{D}$ because stronger stimuli led to suprathreshold activation of pyramidal cells, indicated by the population spike (blue arrow). A fiber volley (black arrow) precedes the MF fEPSP recorded in stratum lucidum (red arrow). At a longer latency, an fEPSP was recorded in stratum radiatum (green arrow). E2, Left, Field potentials corresponding to higher stimulus strengths. Right, The CSD shows an early sink in stratum lucidum (red arrow) followed by a sink in the cell layer reflecting the population spike (blue arrow). Afterward, there is a sink in stratum radiatum (green arrow). $F \mathbf{F}$, Top, A representative recording of MF-evoked fEPSPs recorded in stratum lucidum in response to two identical stimuli, $40 \mathrm{~ms}$ apart, illustrating paired pulse facilitation, a characteristic of the MF pathway (Salin et al., 1996; Kamiya

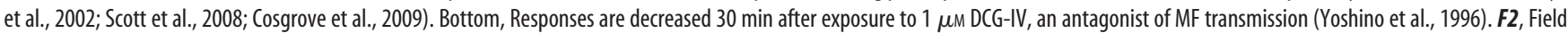
potentials and a CSD analysis of the same slice as E2, 30 min after adding $1 \mu \mathrm{m} \mathrm{DCG-IV} \mathrm{to} \mathrm{the} \mathrm{ACSF.}$

Population spike amplitude. The amplitude of the population spike was defined as the difference between the prestimulus baseline and the peak of the population spike (Scharfman, 1997). Care was taken to record the population spike at a site in stratum pyramidale where it was maximal, which typically was on the border of the pyramidal cell layer and stratum oriens, analogous to area CA1 (Scharfman et al., 2003), rather than a site close to stratum lucidum, where the population spike can be recorded, but is not the site where it is maximal.

Current source density. Current source density (CSD) analysis was conducted using field potential recordings that began at the border of the alveus with stratum oriens in area CA3b and perpendicular to the CA3 pyramidal cell layer, ending in stratum lacunosum-moleculare at a location that was adjacent to the lateral tip of the superior blade of the DG (Fig. 1). Recordings were $\sim 25 \mu \mathrm{m}$ apart and the same depth in the slice, typically $50 \mu \mathrm{m}$. Intervals between sites were monitored using a dissecting microscope (Stemi SV6, Carl Zeiss). The one-dimensional CSD profile was calculated offline using MATLAB (Mathworks) by deriving the second spatial derivative of the local field potential recordings using a 3 -point formula. The CSD represents the transmembrane sink and source currents that generate the recorded field potential profile.

\section{Immunocytochemistry}

Perfusion and processing

After deep anesthesia (urethane, $4 \mathrm{~g} / \mathrm{kg}$, intraperitoneally), animals were perfused through the aorta with $4 \%$ paraformaldehyde, $\mathrm{pH} 7.4$, as previously described (Scharfman et al., 2002). Brains were left in the skull overnight at $4^{\circ} \mathrm{C}$ and removed the next day for dynorphin immunocytochemistry. They were postfixed in $4 \%$ paraformaldehyde at $4^{\circ} \mathrm{C}$ and cut on a vibratome into $50-\mu \mathrm{m}$-thick sections. For BDNF immunocyto- chemistry, the brains were removed after perfusion-fixation and placed in $2 \%$ paraformaldehyde at $4^{\circ} \mathrm{C}$ for $2 \mathrm{~h}$. They were cryoprotected by immersion in $30 \%$ sucrose dissolved in $0.1 \mathrm{~m}$ phosphate buffer. Sections (40 $\mu \mathrm{m}$ thick) were cut on a cryostat (Minotome Plus, International Equipment Company) the next day. Sections were processed that day, as described in Immunocytochemistry: dynorphin.

The antibody to dynorphin $\mathrm{B}_{1-13}$ (kindly provided by Dr. Teresa Milner) has been used previously to evaluate the MF pathway (Pierce et al., 1999). The polyclonal antibody to BDNF (kindly provided by AmgenRegeneron Partners) has also been used previously and shown robust BDNF immunoreactivity (ir) in the MF pathway (Conner et al., 1997; Yan et al., 1997; Scharfman et al., 2002, 2003). The monoclonal antibody to BDNF was used because previous studies have shown that staining with this antibody led to a qualitatively similar pattern of BDNF-ir as the polyclonal antibody (Scharfman et al., 2007). Notably, processing sections in the absence of the primary antibody failed to produce MF BDNF-ir.

\section{Immunocytochemistry: dynorphin}

Sections were processed with a polyclonal antibody to dynorphin B made in rabbit (Pierce et al., 1999), using free-floating sections that were initially washed twice ( 5 min each) in $0.1 \mathrm{M}$ Tris buffer, $\mathrm{pH} 7.6$, and treated with $1 \% \mathrm{H}_{2} \mathrm{O}_{2}$ made in $0.1 \mathrm{M}$ Tris buffer ( $\mathrm{pH} 7.6 ; 30 \mathrm{~min}$ ). Sections were then washed in $0.1 \mathrm{M}$ Tris buffer ( $\mathrm{pH} 7.6 ; 5 \mathrm{~min}$ ) and treated with $0.25 \%$ Triton X-100 dissolved in $0.1 \mathrm{~m}$ Tris buffer (Tris A; $10 \mathrm{~min}$ ), followed by $0.25 \%$ Triton X-100 and $0.005 \%$ BSA in $0.1 \mathrm{~m}$ Tris buffer (Tris B; 10 $\mathrm{min})$. Sections were then treated with $10 \%$ normal goat serum diluted in Tris B for $45 \mathrm{~min}$. Sections were subsequently washed in Tris A (10 min) followed by Tris B (10 min) and incubated in antisera (1:1000; diluted in 
Tris B) for $24 \mathrm{~h}$ on a rotating shaker. The next day, sections were treated with Tris A (10 min) followed by Tris B (10 min) and then incubated for 45 min with a biotinylated secondary antibody against rabbit IgG made in goat (1:400, Vector Laboratories). Sections were washed in Tris A (10 $\min$ ), then $0.25 \%$ Triton X-100 and $0.005 \%$ BSA in $0.5 \mathrm{M}$ Tris buffer (Tris $\mathrm{D} ; \mathrm{pH} 7.6 ; 10 \mathrm{~min}$ ), and finally incubated for $1 \mathrm{~h}$ in avidin-biotin horseradish peroxidase complex diluted in Tris (ABC Standard kit, 1:1000; Vector Laboratories). Immunoperoxidase labeling was developed in $\mathrm{DAB}(50 \mathrm{mg} / 100 \mathrm{ml}$ of $0.1 \mathrm{M}$ Tris buffer $)$ with $200 \mathrm{mg}$ of D-glucose, $0.3 \mathrm{mg}$ of glucose oxidase, and $40 \mathrm{mg}$ of ammonium chloride, and then washed three times ( $5 \mathrm{~min}$ each) in $0.1 \mathrm{~m}$ Tris buffer, $\mathrm{pH}$ 7.6. Sections were mounted on subbed slides, allowed to dry overnight, and then dehydrated in a series of ethanol solutions (70\%, $5 \mathrm{~min} ; 95 \%, 5 \mathrm{~min}, 100 \%, 10$ $\mathrm{min}, 100 \%, 10 \mathrm{~min}$ ), cleared in xylene (10 min), and coverslipped with Permount (Fisher Scientific). The sections were viewed on a brightfield microscope (BX51, Olympus of America) and photographed using a digital camera (Retiga 2000R, Q Imaging) using ImagePro (Media Cybernetics). To allow comparisons in the figures, micrographs of sections from different experimental groups were taken using the same light and camera settings.

\section{Immunocytochemistry: BDNF}

Sections were first washed in $0.05 \mathrm{~m}$ potassium PBS (KPBS, pH 7.3) and then treated with $0.5 \% \mathrm{H}_{2} \mathrm{O}_{2}$ in $\mathrm{KPBS}$ for $30 \mathrm{~min}$. After a 5 min wash in KPBS, sections were incubated in $10 \%$ normal goat serum for the polyclonal antibody ( $10 \%$ horse serum for the monoclonal antibody), plus $1 \%$ BSA and $0.25 \%$ Triton X-100 in KPBS for 20 min. Sections were incubated in antisera (polyclonal: 1:30,000; Scharfman et al., 2002, 2003; monoclonal: 1:1000; Sigma-Aldrich; Scharfman et al., 2007) in 1\% BSA and $0.25 \%$ Triton X-100 in KPBS for $48 \mathrm{~h}$ at $4^{\circ} \mathrm{C}$ and subsequently rinsed 10 times (10 min each) in $0.25 \%$ BSA and $0.025 \%$ Triton X-100 in $0.01 \mathrm{M}$ KPBS. Sections were then incubated in a biotinylated secondary antibody against rabbit IgG made in goat (1:400; Vector Laboratories) for the polyclonal antibody (or biotinylated secondary antibody against mouse IgG made in horse (1:400; Vector Laboratories) for the monoclonal antibody) and $1 \%$ BSA and $0.025 \%$ Triton X-100 in KPBS for $1 \mathrm{~h}$, followed by ABC (ABC Standard kit; 1:1000; Vector Laboratories) in 1\% BSA in KPBS for $1 \mathrm{~h}$. Sections were rinsed in KPBS followed by Tris buffer, and reacted with $\mathrm{DAB}$ using methods identical to those described above for dynorphin, except $10 \mathrm{~mm} \mathrm{NiCl}_{2}$ was added to the DAB solution.

\section{Data analysis}

Quantification of immunocytochemical data used ImagePro (Media Cybernetics). The same light settings were used for all procedures. For measurement of BDNF in the MF plexus in stratum lucidum, a square region of interest (ROI; $\sim 50 \mu \mathrm{m}^{2}$ ) was placed over the terminal field at the border of CA3a with CA2, where immunoreactivity was greatest (Scharfman et al., 2003, 2007) (see Fig. 9H1). Three measurements (spanning the terminal field of the MFs; see Fig. 9H1) of the grayscale value (scale, $0-255$; for the purposes of this analysis, 0 was defined as white and 255 was defined as black) were made for a given section and averaged. Three measurements were also made of the area in stratum radiatum beside the ROI, where immunoreactivity was weak. The average of the three measurements in stratum radiatum was subtracted from the average of the three measurements in stratum lucidum to give the final grayscale value for a given section. The procedure was repeated for two other sections at a similar septotemporal level. The average value from the three sections was used as the best estimate for that animal. A similar procedure was used to determine whether dynorphin-ir in stratum lucidum was increased or decreased in Gdx rats compared with sham rats.

To determine whether mossy fiber sprouting occurred, a different method was used: an ROI was drawn around the MF plexus of CA3a in stratum lucidum and stratum oriens in the section with the most widespread MF sprouting in stratum oriens (see Fig. 9G1). This ROI was then used as a template for all sections to measure the mean grayscale value within the ROI. The template was moved to stratum radiatum to measure the background (see Fig. 9G1), which was subtracted.

\section{Pharmacology}

Administration of drugs to hippocampal slices

Dihydrotestosterone (DHT; Sigma-Aldrich) and $5 \alpha$-androstane- $3 \alpha$, $17 \beta$-diol (Adiol; Sigma-Aldrich) were dissolved in $100 \%$ ethanol as a $1 \mathrm{M}$ stock solution and stored at $4{ }^{\circ} \mathrm{C}$; the stock solution was diluted in $\mathrm{NaCl}-\mathrm{ACSF}$ on the day of the experiment to reach the final concentration (50 nM). K252a (LC Labs) was dissolved in DMSO (SigmaAldrich) as a $1 \mathrm{~m}$ stock solution and stored at $4^{\circ} \mathrm{C}$. It was diluted in $\mathrm{NaCl}-\mathrm{ACSF}$ on the day of the experiment to reach the final concentration (300 nм). TrkB-IgG (R\&D Systems), control IgG (R\&D Systems), and 2-(2,3-dicarboxycyclopropyl)-glycine (DCG-IV; Tocris Bioscience) were dissolved in $0.9 \% \mathrm{NaCl}$, stored at $4^{\circ} \mathrm{C}$ as a concentrated stock solution ( $1 \mathrm{~mm}$ ), and diluted in NaCl-ACSF on the day of use. Testosterone and placebo time-release pellets (25 mg/pellet, $21 \mathrm{~d}$ release; \#A-151 and \#C-111, respectively; Innovative Research of America) were stored at room temperature in the dark. The testosterone dose was sufficient to replace normal serum testosterone levels (Fig. 2F3).

\section{Hormone replacement}

A 1/4-inch incision was made between the shoulder blades immediately after gonadal removal or sham treatment while the animal was still anesthetized. A 1/8-inch-diameter pellet was inserted under the skin. Sterile sutures were used to close the incision.

Testosterone ELISA was conducted to determine circulating levels of testosterone. Trunk blood was collected in $15 \mathrm{ml}$ of centrifuge tubes at the time of death and placed at room temperature for 20-30 min. Serum was separated by centrifugation $\left(3000 \mathrm{rpm}, 15 \mathrm{~min}, 23^{\circ} \mathrm{C}\right)$ and frozen $\left(-20^{\circ} \mathrm{C}\right)$ until use. A testosterone ELISA was performed using methods provided by the manufacturer (Mouse and Rat Testosterone Kit, Calbiochem). Details were provided previously (Chakraborty et al., 2012).

\section{Statistics}

Data are expressed as mean \pm SEM. The $p$ criterion was 0.05 . No more than two slices were used for a given animal. Student's $t$ test were twotailed and conducted using Microsoft Excel 2007 (Microsoft). Fisher's exact test, $\chi^{2}$ test, ANOVA, repeated-measures ANOVA (RM-ANOVA), ANCOVA, and nonparametric Kruskal-Wallis ANOVA were performed using Prism (GraphPad). When reporting the results of ANOVA or RM-ANOVA, interactions between factors are reported in the Results only in those cases where they were statistically significant. For parametric ANOVA, where there was inhomogeneity of variance, which was determined by Bartlett's test (Prism), data were log-transformed before statistical analysis (Zivin and Bartko, 1976).

\section{Results}

\section{MF transmission is increased in Gdx rats}

Recording procedures to study MF transmission

We first confirmed that our stimulation and recording procedures evoked responses that were mediated by MFs in adult male rats that were the same age as those that would be used for experiments ( $\sim 2$ months old). As shown in Figure $1 A-C$, a stimulating electrode was placed at the crest of the DG in the SGZ, with recording electrodes in stratum lucidum of area CA3b. fEPSPs had the characteristics previously reported for MF transmission: (1) short latency to onset of the fEPSP $(<4 \mathrm{~ms})$, consistent with monosynaptic transmission; (2) robust paired pulse facilitation (Salin et al., 1996; Kamiya et al., 2002; Scott et al., 2008; Cosgrove et al., 2009); and (3) blockade by $1 \mu \mathrm{M}$ DCG-IV, a metabotropic glutamate receptor subtype II agonist that blocks MF transmission (Figure 1D-F) (Yoshino et al., 1996). Another characteristic, a fiber volley before the fEPSP, occurred when stimulus strength was sufficiently strong (Fig. $1 E$, black arrow).

Laminar analysis of the response to stimulation in CA3b showed that the fEPSP recorded in stratum lucidum was followed by a later fEPSP that was only recorded in stratum radiatum, and reversed polarity in the pyramidal cell layer (Fig. 1D1,E1). CSD analysis (Fig. 1D2,E2) showed a short-latency sink in stratum 
A

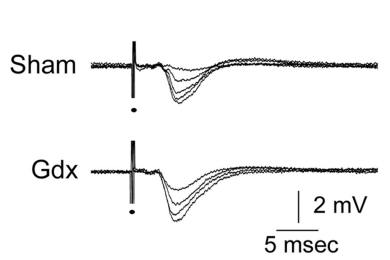

E Latency

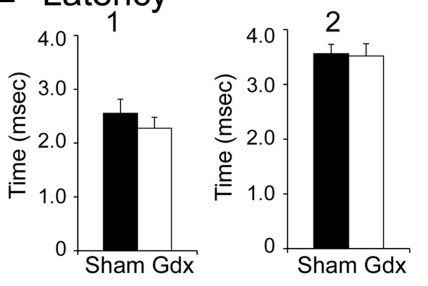

B fEPSP slope

- Sham $n=10$ slices (8 rats)

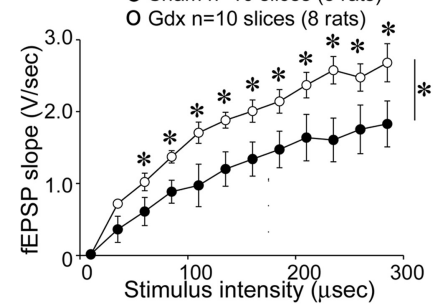

$\mathrm{F}_{1}$
C Fiber volley
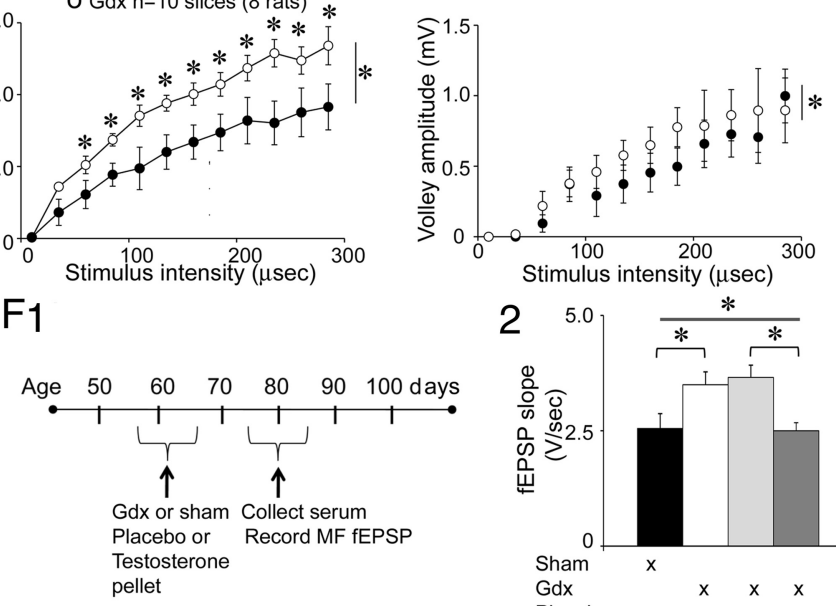

2

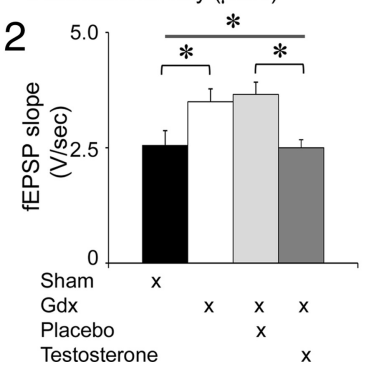

D Volley vs. slope
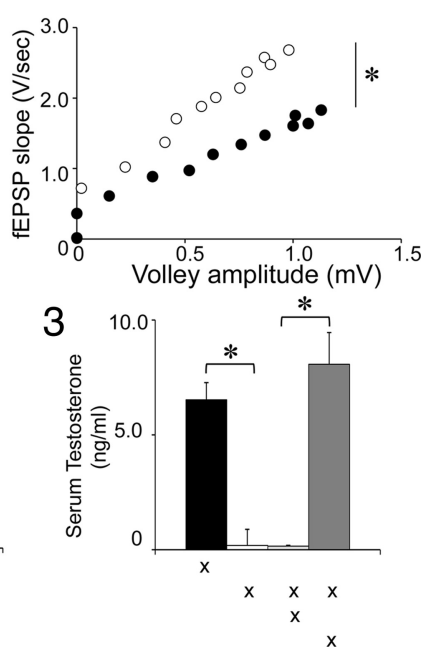

Figure 2. Slices from Gdx rats exhibit larger MF fEPSPs than sham rats. $\boldsymbol{A}$, Representative examples of MF fEPSPs are shown for a sham (top) and Gdx rat (bottom) that had surgery $\sim 2$ weeks previously. The responses to a range of stimulus intensities are superimposed. $\boldsymbol{B}$, The input-output relation is shown for MF fEPSP slope from sham (black) and Gdx (white) rats. Gdx rats had significantly greater fEPSP slopes by two-way RM-ANOVA: ${ }^{*} p<0.05$ (asterisk to the right of the vertical bar; asterisks above data points denote significance after post hoc tests; for this and all other figures, all statistical comparisons are provided in the text). $\boldsymbol{C}$, The input-output relation is shown for fiber volleys from the same sham and Gdx rats. Differences were significant by ANOVA 4-parameter linear regression analysis $(p<0.001)$. D, MF fEPSP slope is plotted against fiber volley amplitude for the same data. The slopes were significantly different: ${ }^{*} p<0.05$ (ANCOVA). $\boldsymbol{E}$, The mean latencies to (1) the onset of the fiber volley and (2) the onset of MF fEPSPs (evoked by a minimal stimulus) are shown; differences were not significant (Student's $t$ test, $p>0.05$ ). F1, A schematic illustrates the experimental timeline for $\mathrm{Gdx}$ rats that were implanted with a subcutaneous pellet containing testosterone or placebo. Comparisons were made to sham and $\mathrm{Gdx}$ rats that were untreated. F2, Comparison of MF fEPSP slope showed group differences: ${ }^{*} p<0.05$ (asterisk over the bar, one-way ANOVA). Gdx rats that were untreated (white) had significantly greater fEPSP slopes than sham rats that were untreated (black): ${ }^{*} p<0.05$ (asterisk over the bracket; post hoc test). Gdx rats treated with placebo (light gray) had significantly greater fEPSP slopes than Gdx rats treated with testosterone (dark gray): ${ }^{*} p<0.05$ (asterisk over the bracket; post hoc test). fEPSPs in slices of Gdx rats treated with testosterone were similar to sham rats. Gdx rats that were treated with placebo (dark gray) were similar to $\mathrm{Gdx}$ rats that were untreated (white): $p>0.05$ (post hoc tests). F3, ELISA showed that serum testosterone levels were at the lower limit of the assay for placebo and untreated Gdx rats. Differences between sham rats and Gdx rats treated with testosterone were not significant (Kruskal-Wallis AN0VA, followed by post hoc test, $p>0.05$ ), suggesting that testosterone administration restored testosterone levels to a comparable range as sham rats. Differences between untreated sham and untreated $G d x$ rats were significant; differences between Gdx rats treated with placebo and Gdx rats treated with testosterone were also significant: ${ }^{*} p<0.05$ (asterisks above the brackets; Kruskal-Wallis ANOVA followed by post hoc tests).

lucidum and a longer latency sink in stratum radiatum, suggesting a monosynaptic fEPSP corresponding to activation of MFs, followed by a disynaptic fEPSP reflecting activation of recurrent collaterals of pyramidal cells in stratum radiatum. The field potentials recorded in stratum lucidum and the cell layer were reduced $>90 \%$ by DCG-IV ( $1 \mu \mathrm{M} ; n=8$ slices, 3 rats; Fig. $1 F$ ). Notably, $1 \mu \mathrm{M}$ DCG-IV had no detectable effect on fEPSPs evoked by Schaffer collateral stimulation, recorded in stratum radiatum of CA1 (2 slices from 2 sham controls; fEPSP slope 30 min after DCG-IV: $99.4 \%$ of pre-DCG-IV baseline).

A small fEPSP in stratum radiatum remained after DCG-IV (Fig. 1F2), which could be due to the fact that DCG-IV did not block the response entirely. It is also possible that activation of CA3 pyramidal cell axons in the hilus (Scharfman, 2007) led to activation of recurrent collaterals to area CA3 pyramidal cell dendrites in stratum radiatum. For these reasons, the term "MF fEPSP" is used below to refer only to short-latency fEPSPs recorded in stratum lucidum. "Recurrent fEPSP" is used below to refer only to the long latency fEPSPs recorded in stratum radiatum. It should be noted that the term "MF LTP" is used with caution below because we cannot rule out a possible contribution of the recurrent collateral pathway during LTP induction.

\section{$M F$ fEPSPs are increased in Gdx rats}

For the comparisons of MF fEPSPs between Gdx and sham rats, animals had surgery at ages that were not different (Gdx: $68.4 \pm$ 2.4-d-old; sham: $57.2 \pm 3.6$-d-old; $n=10$ slices from 8 rats/ group; Student's $t$ test, $p=0.973)$, and hippocampal slices were made at similar delays after surgery (Gdx: $14.5 \pm 1.6 \mathrm{~d}$; sham:
$13.6 \pm 1.0 \mathrm{~d} ; n=10$ slices from 8 rats/group; Student's $t$ test, $p=$ $0.736)$. As shown in Figure $2 A$, MF fEPSPs were largest in Gdx rats ( $n=10$ slices, 8 rats/group). There was a significant effect of $\mathrm{Gdx}$ on the input-output relation for fEPSP slope (two-way RM-ANOVA; $F_{(1,198)}=5.710 ; p=0.028$; Fig. $2 B$ ) and a significant interaction between treatment and stimulus strength $\left(F_{(11,198)}=2.566 ; p=0.005\right)$ with significantly larger fEPSP slopes in Gdx rats at all stimulus strengths except the two weakest intensities (Student's $t$ test, $p<0.05$; Fig. $2 B$ ). Results were similar for amplitude; there was a significant effect of Gdx (two-way RM-ANOVA; $\left.F_{(1,198)}=66.086 ; p<0.0001\right)$ and an interaction between Gdx and stimulus strength $\left(F_{(11,198)}=14.986 ; p<0.0001\right)$, with fEPSPs from Gdx rats greater in sham rats at all stimulus strengths except the weakest stimuli (Student's $t$ test, $p<0.05$ ).

When fiber volleys were measured, there was no significant effect of $\mathrm{Gdx}$ on the input-output relation by two-way RM-ANOVA $\left(F_{(1,198)}=0.722 ; p=0.407\right.$; Fig. $\left.2 C\right)$. However, ANOVA-based 4-parameter linear regression analysis (Scharfman et al., 2007) indicated that fiber volley amplitudes in Gdx rats were significantly higher than those for sham-operated controls $\left(F_{(1,28)}=\right.$ 18.92; $p<0.001)$.

Gdx rats exhibited a greater MF fEPSP slope for a given fiber volley amplitude (Fig. 2D). Excluding the MF fEPSPs elicited at the two weakest intensities (where fiber volleys were not present), the slope of the relation was significantly greater for Gdx rats (linear regression analysis; $F_{(1,17)}=11.486 ; p=0.004$; Fig. $\left.2 D\right)$.

Although fEPSPs were larger in Gdx rats, there were no differences in latencies. First, we measured the latency to onset of the 
A1
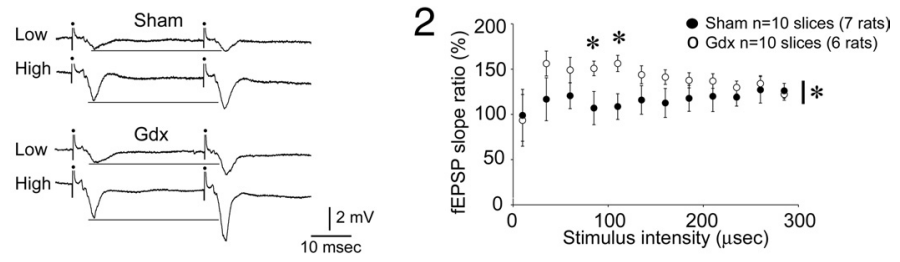

B1
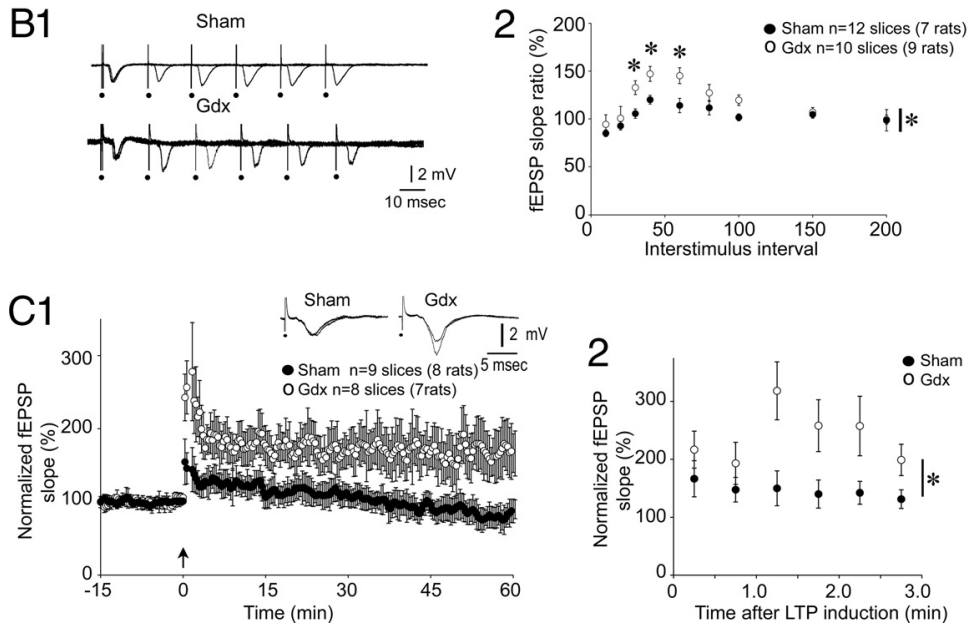

Figure 3. Increased PPF, post-tetanic potentiation (PTP) and LTP in Gdx rats compared with sham controls. A1, MF fEPSPs elicited by low or high stimulus strengths ( 35 or $110 \mu \mathrm{s}$ ) are shown for a sham (top) and Gdx (bottom) rat. Horizontal lines are shown to facilitate comparisons. A2, Mean PPF was significantly greater in Gdx rats compared with sham rats when the stimulus strength was intermediate. $\boldsymbol{A}, \boldsymbol{B},{ }^{*} p<0.05$ for a main effect of Gdx on PPF by two-way RM-ANOVA (asterisk beside the vertical bar). ${ }^{*} p<0.05$ for post hoc tests (asterisk above the symbols). B1, Examples of PPF recorded from a slice of a Gdx and sham rat. In each case, responses are superimposed, each using a half-maximal stimulus and 20-100 ms interstimulus intervals. B2, Mean PPF was greater in Gdx rats by two-way RM-ANOVA $\left({ }^{*} p<0.05\right.$, asterisk by the vertical bar) followed by post hoc tests $\left({ }^{*} p<0.05\right.$, asterisk above the symbols) for the 30-60 ms interstimulus intervals. C1, Normalized fEPSP slope measurements are shown for slices from $\mathrm{Gdx}$ rats $(\bigcirc)$ and sham $(O)$ before and after LTP induction (two $25 \mathrm{~Hz}, 1 \mathrm{~s}$ trains, $10 \mathrm{~s}$ apart, at the arrow). There was greater LTP in Gdx rats (Student'st test at 60 min after LTP induction; $p<0.05$ ). C2, PTP over the first 3 min after LTP induction was greater in slices from $\mathrm{Gdx}$ rats compared with sham rats: ${ }^{*} p<0.05$ (two-way RM-ANOVA).

peak of the maximal fiber volley and found that there were no significant differences between experimental groups (Gdx: $1.96 \pm 0.33 \mathrm{~ms}$; sham: $2.34 \pm 0.26 \mathrm{~ms}$; Student's $t$ test; $p=0.370$; Fig. 2E1). Then we measured the latencies to onset of MF fEPSPs; both minimal and maximal fEPSPs were measured because latency varies depending on the stimulus strength (latency is longest when stimuli are weak). There were no differences between fEPSPs of Gdx and sham rats when stimuli were minimal (35 $\mu$ s; Gdx: $3.84 \pm 0.38 \mathrm{~ms}$; sham: $3.81 \pm 0.23 \mathrm{~ms}$; Student's $t$ test, $p=$ 0.952; Fig. 2E2) and no differences in the maximal fEPSPs (Gdx: $3.38 \pm 0.28 \mathrm{~ms}$; sham: $3.36 \pm 0.12 \mathrm{~ms}$; Student's $t$ test, $p=0.957$ ).

To confirm that effects of $\mathrm{Gdx}$ were the result of a reduction in serum levels of testosterone, we determined whether testosterone replacement to Gdx rats blocked effects of Gdx on MF transmission. For this purpose, a time-release pellet of either testosterone or placebo was inserted subcutaneously at the time of surgery (Fig. 2F1). There were four experimental groups: $\mathrm{Gdx}$ rats treated with a testosterone pellet (10 slices, 5 rats), Gdx rats that received a placebo pellet (12 slices, 6 rats), untreated Gdx rats (27 slices, 17 rats), and untreated sham controls (16 slices, 10 rats). MF fEPSPs were tested $\sim 2$ weeks after surgery. There were differences between the four groups (one-way ANOVA; $F_{(3,64)}=2.668 ; p=$ 0.015 ), with smaller fEPSP slopes in Gdx animals that received testosterone compared with Gdx rats treated with placebo (Student's $t$ test, $p=0.008$; Fig. 2F2). MF fEPSPs of Gdx animals that received placebo were not significantly different from fEPSPs of untreated Gdx rats (Student's $t$ test, $p=0.651$ ), and there were no significant differences between $\mathrm{Gdx}$ rats that received testosterone and untreated sham controls (Student's $t$ test, $p=$ 0.702; Fig. 2F2).

To confirm that serum testosterone levels were restored by testosterone pellets, testosterone was measured by ELISA from trunk blood collected at the time of death. Gdx rats that were untreated or treated with placebo had very low testosterone levels; those that were below the lower limit of the assay were assigned the lower limit for their testosterone value $(0.10 \mathrm{ng} / \mathrm{ml}$; Fig. 2F3). There were significant differences between the four experimental groups (Kruskal-Wallis statistic, 32.584, $p<0.0001$; Fig. 2F3). Circulating testosterone levels in $\mathrm{Gdx}$ rats treated with testosterone $(8.08 \pm 1.4 \mathrm{ng} / \mathrm{ml} ; n=5$ rats $)$ were significantly greater than $\mathrm{Gdx}$ rats treated with placebo $(0.16 \pm 0.04 \mathrm{ng} / \mathrm{ml}$; $n=6$; Dunn's multiple-comparisons test, $p>0.05$; Fig. 2F3). However, Gdx rats treated with testosterone were not significantly different from untreated sham controls $(6.52 \pm 0.75 \mathrm{ng} / \mathrm{ml} ; n=10 ; p>0.05$; Fig. 2F3). The mean value for serum testosterone of Gdx rats treated with placebo was not significantly different from Gdx rats that were untreated $(0.19 \pm 0.09 \mathrm{ng} /$ $\mathrm{ml} ; n=6 ; p>0.05$; Fig. 2F3). These data confirmed that Gdx reduced serum testosterone to a negligible level and testosterone treatment increased it to levels that were normal for the strain and age of rats that were used.

\section{PPF, post-tetanic potentiation, and LTP are increased in}

Gdx rats

PPF of MF fEPSPs was greater in Gdx rats than sham controls (Fig. 3). PPF was tested using half-maximal stimulation and a 40 $\mathrm{ms}$ interstimulus interval because these are parameters where PPF is typically robust (Scharfman, 1997; Scharfman et al., 2003, 2007). PPF was significantly greater in slices from Gdx rats compared with sham controls (Gdx: $166.8 \pm 3.2 \% ; n=15$ slices, 12 rats; sham: $121.0 \pm 3.2 \%$; 14 slices, 12 rats; Student's $t$ test, $p=0.006)$.

We also evaluated PPF in additional rats (Gdx: 10 slices, 7 rats; sham: $n=10$ slices, 6 rats) using a range of stimulus strengths because PPF has not been evaluated in detail at the ages we used, raising the possibility that PPF in sham rats might have been underestimated using a half-maximal stimulus. There was no significant difference in PPF across stimulus strengths in sham rats (one-way ANOVA; $F_{(11,95)}=0.096 ; p=0.880$ ). PPF in Gdx rats was significantly greater than sham rats at two stimulus strengths in the middle of the input-output relation (two-way RM-ANOVA; $F_{(11,154)}=7.907 ; p=0.014$; Student's $t$ test, $p<$ 0.05 for 110 and $135 \mu$ s; Fig. 3A2).

Next, PPF was evaluated using a range of interstimulus intervals $(10,20,30,40,60,80,100,150$, and $200 \mathrm{~ms}$; Gdx: 10 slices, 9 rats; sham: 12 slices, 7 rats) with a half-maximal stimulus strength. As shown in Figure 3B, Gdx influenced PPF (two-way RM-ANOVA; $\left.F_{(1,160)}=21.560 ; p<0.001\right)$ with a significant 

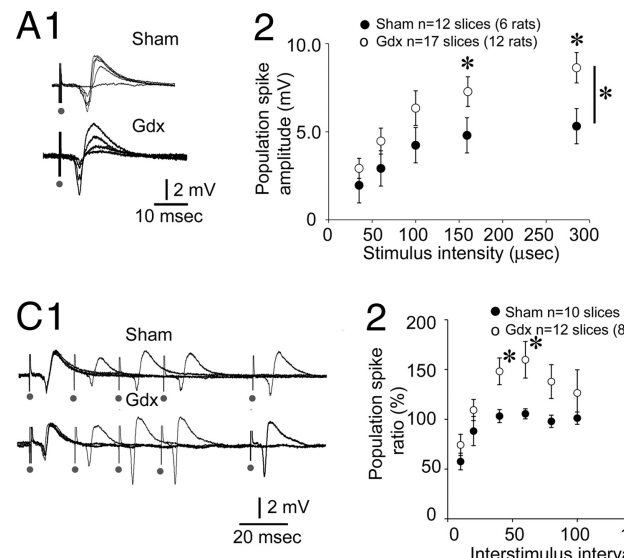

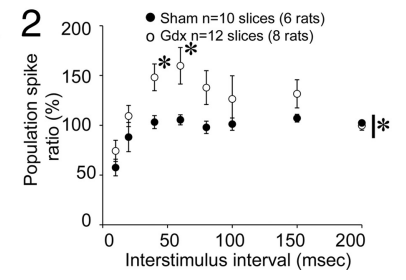

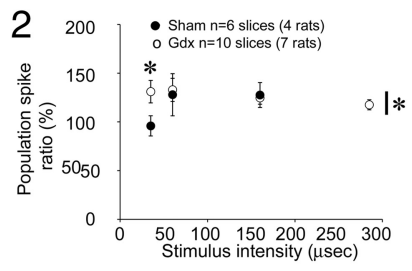

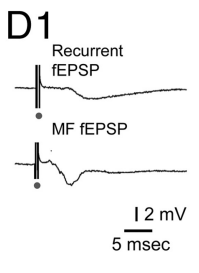

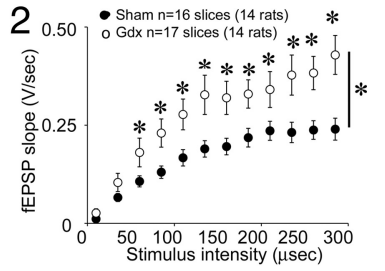

Figure 4. Larger population spikes and greater recurrent fEPSPs in Gdx rats compared with sham rats. $\mathbf{A 1}$, Superimposed responses to MF stimulation recorded in stratum pyramidale. A2, An input-output curve for population spike amplitude shows that amplitudes were greater in Gdx rats: ${ }^{*} p<0.05$ (two-way RM-ANOVA; asterisk by the vertical bar). Significance of post hoc tests is denoted by asterisks above the symbols. B1, PPF in a slice from a sham and Gdx rat. PPF was elicited using many stimulus strengths and a constant ( 40 ms) interstimulus interval. B2, ${ }^{*}$ Mean PPF was greater in $\mathrm{Gdx}$ rats at the lowest stimulus intensities. C, Representative examples (C1) and quantification (C2) of PPF of population spike amplitude using a half-maximal stimulus strength and a range of interstimulus intervals (10-200 ms). *PPF was greater in Gdx rats at the 40 and $60 \mathrm{~ms}$ intervals. D1, A representative response in stratum radiatum (top) and stratum lucidum (bottom) to the same MF stimulus shows the longer latency of the response recorded in stratum radiatum, which we interpret to be a disynaptic fEPSP mediated by recurrent collaterals of pyramidal cells (see Fig. 1). D2, * Recurrent fEPSP slope was greatest in slices from Gdx rats.

interaction between interstimulus interval and effect of $\mathrm{Gdx}$ $\left(F_{(8,160)}=3.453 ; p=0.001\right)$. PPF was greater in Gdx rats when interstimulus intervals were intermediate (30, 40, or $60 \mathrm{~ms}$; Student's $t$ test, $p<0.05$; Fig. 3B1,B2).

To examine post-tetanic potentiation (PTP) and LTP, we planned to use TBS, but several slices from Gdx rats exhibited spreading depression (SD) in response to TBS (described further below). Therefore, LTP was induced using two $25 \mathrm{~Hz}$ trains, $1 \mathrm{~s}$ in duration, $10 \mathrm{~s}$ apart; a similar procedure $(25 \mathrm{~Hz}, 1 \mathrm{~s}$ or $25 \mathrm{~Hz}, 5 \mathrm{~s})$ has been shown to elicit MF LTP in 18- to 25-d-old Wistar rats (Kwon and Castillo, 2008), which we confirmed in 30-d-old Sprague Dawley rats (147.7 $\pm 6.2 \% ; n=3$ slices from 3 rats). As shown in Figure 3C1, Gdx rats exhibited LTP but sham rats did not (presumably because of their age; Gdx: $169.1 \pm 20.7 \% ; n=9$ slices, 8 rats; sham: $88.3 \pm 14.1 \% ; n=8$ slices, 7 rats; Student's $t$ test, $p=0.008)$. Both groups exhibited robust PTP, but Gdx rats had greater PTP (two-way RM-ANOVA for the first 3 min after LTP induction; $F_{(1,140)}=9.231 ; p=0.009$; Student's $t$ test, $p<$ 0.05; Fig. 3C2).

\section{Gdx increases MF-evoked field potentials recorded outside stratum lucidum}

Responses to MF stimulation were also recorded in the pyramidal cell layer to evaluate the extent that an increase in MF transmission led to enhanced pyramidal cell output, reflected by an increase in the population spike amplitude (Fig. 4A1-A2; Gdx: 17 slices, 12 rats; sham: 12 slices, 6 rats). An input-output curve for the population spike showed that there was a significant effect of Gdx (two-way RM-ANOVA; $F_{(1,108)}=4.737 ; p=0.038$; Fig. $4 A 2$ ). There was an interaction between surgical status ( $\mathrm{Gdx}$ vs sham $)$ and stimulus strength $\left(F_{(4,108)}=3.749 ; p=0.007\right)$, with a significant increase in population spike amplitude in $\mathrm{Gdx}$ rats at the highest stimulus intensities (Student's $t$ test, $p<0.05$; Fig. 4A2).

PPF of the population spike was greater in Gdx rats (halfmaximal stimulus intensity; $40 \mathrm{~ms}$ interstimulus interval; Gdx: $137.8 \pm 2.3 \% ; n=18$ slices, 13 rats; sham: $109.1 \pm 1.9 \% ; n=11$ slices, 7 rats; Student's $t$ test, $p=0.040$; Fig. $4 B, C$ ). When multiple stimulus strengths were compared in a subset of these slices (Gdx: 10 slices, 7 rats; sham: 7 slices, 6 rats), two-way RM-ANOVA showed that there was an interaction between surgical treatment $\left(\mathrm{Gdx}\right.$ or sham) and stimulus strength $\left(F_{(3,42)}=\right.$ 3.257; $p=0.031$ ) with PPF in slices from Gdx rats greater at the lowest intensity (Student's $t$ test, $p<0.05$ ) but not higher intensities (Student's $t$ test, $p>0.05$; Fig. 4B2).

PPF was also evaluated using a range of interstimulus intervals and a half-maximal stimulus strength (Gdx: 12 slices, 8 rats; sham: 10 slices, 6 rats). Two-way RM-ANOVA showed that there was an interaction between surgical treatment and interstimulus interval $\left(F_{(1,140)}=4.072 ; p=0.033\right)$ with significantly greater PPF in Gdx rats at 40 and 60 ms interstimulus intervals (Student's $t$ test, $p=0.016$ and $p=0.028$, respectively; Fig. $4 C 1, C 2$ ). There were no significant differences between Gdx and sham rats at the short interstimulus intervals, when paired pulse inhibition typically occurs ( 10 or $20 \mathrm{~ms}$ intervals; Student's $t$ test, $p=0.162$ and $p=0.220$ respectively; Fig. 4C1,C2). Therefore, Gdx rats had greater PPF of the population spike, but there was no effect on paired pulse inhibition.

Another cohort of rats was used to determine whether the delayed fEPSP recorded in stratum radiatum (referred to as the "recurrent fEPSP" below) was affected by Gdx. As shown in Figure $4 D$, recurrent fEPSP slopes were increased in Gdx rats (17 slices, 14 rats) compared with sham controls (16 slices, 14 rats). The input-output relation was significantly different (two-way RM-ANOVA; $\left.F_{(1,341)}=8.095 ; p=0.008\right)$, and there was an interaction between surgical pretreatment and stimulus strength $\left(F_{(11,341)}=3.269 ; p<0.001\right)$ with recurrent fEPSPs of Gdx rats greater than sham at all stimulus strengths except the two lowest intensities (Student's $t$ test, $p<0.05$; Fig. 4D2). The lack of a significant effect at low stimulus intensities is consistent with the idea that recurrent fEPSPs required strong intensities of stimulation, so that pyramidal cells would reach threshold for action potential generation and activate their recurrent collaterals.

The latencies to onset of the recurrent fEPSP were not affected by Gdx. The recurrent fEPSP that was evoked by a weak stimulus (a $35 \mu$ s stimulus) had a $5.68 \pm 0.16$ ms latency to onset in slices from Gdx rats, and latency was $5.69 \pm 0.18 \mathrm{~ms}$ in slices from sham rats (Student's $t$ test; $p=0.965$ ). The latencies to onset of 
A
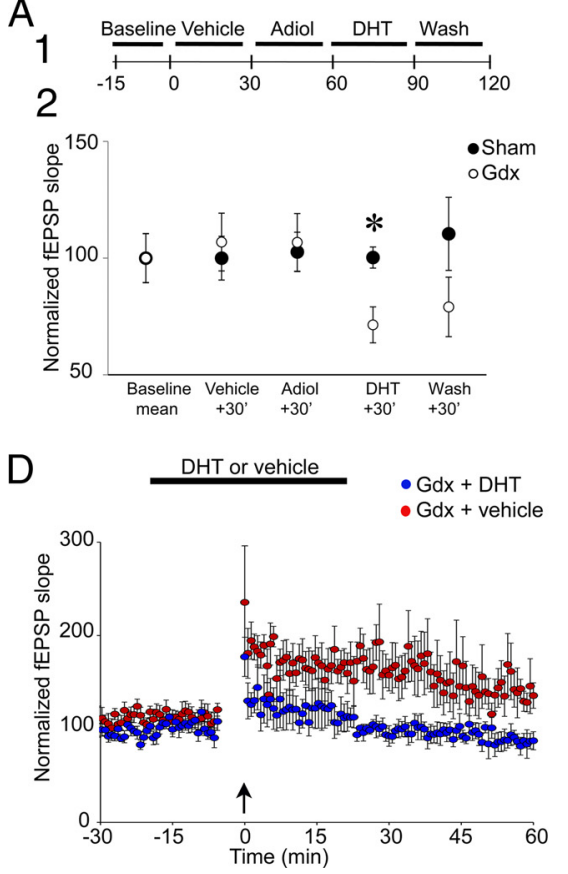

B

1
2

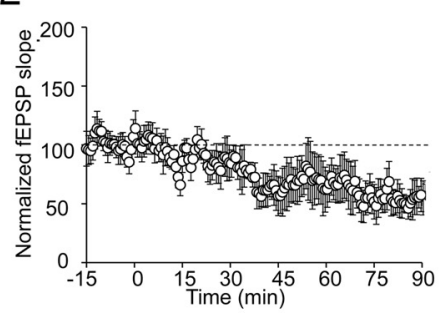

E $\quad$ DHT or vehicle $\quad \cdot \mathrm{Gdx}+\mathrm{DHT}$

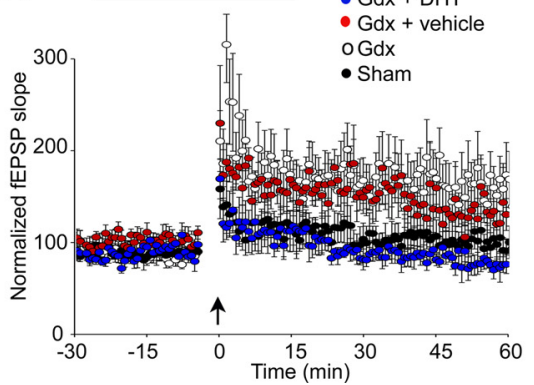

C 1

2
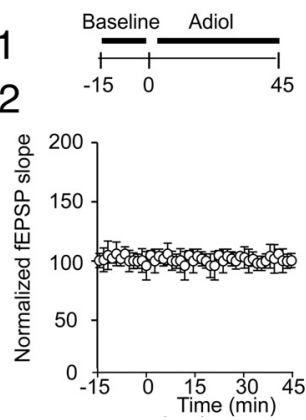

$\mathrm{F}$
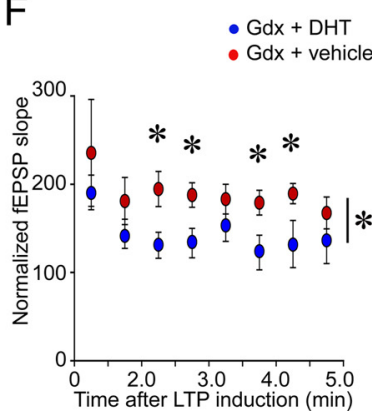

Figure 5. DHT sensitivity of MF transmission and LTP in Gdx rats. A1, A diagram of the experimental timeline is shown. Slices from Gdx rats $(\bigcirc, n=4$ slices, 4 rats $)$ and sham rats $(n=3$ slices, 3 rats) were exposed to vehicle (0.0005\% ethanol) for $30 \mathrm{~min}$ and then $50 \mathrm{~nm}$ Adiol for $30 \mathrm{~min}$, followed by $50 \mathrm{~nm}$ DHT and then wash. A2, MF fEPSP slopes decreased after exposure to DHT in Gdx rats $\left({ }^{*} p<0.05\right.$; one-way RM-ANOVA followed by post hoc tests) but not sham rats ( $p>0.05$; one-way RM-ANOVA). B1, The experimental procedure is shown. Slices from Gdx rats $(n=4$ slices, 4 rats) were exposed to $50 \mathrm{~nm}$ DHT immediately after a $15 \mathrm{~min}$ baseline. $\mathbf{B 2}$, fEPSP slope decreased during exposure to DHT, and the effect persisted after wash. $\mathbf{C 1}$, The experimental procedure is shown. After a $15 \mathrm{~min}$ baseline period, slices from Gdx rats ( $n=5$ slices, 5 rats) were exposed to $50 \mathrm{~nm}$ Adiol for $45 \mathrm{~min}$. $\mathbf{C}$, The results of the experiment diagrammed in $\mathbf{C}$ show that there was no detectable effect. $\boldsymbol{D}$, Slices from Gdx rats were treated (designated by the horizontal bar) with $50 \mathrm{~nm}$ DHT (blue circles, $n=5$ slices, 5 rats) or vehicle (red circles, $n=8$ slices, 8 rats) for 15 min before and after LTP induction (at the arrow). There was greater LTP (measured $60 \mathrm{~min}$ after LTP induction) in DHT-treated slices compared with vehicle ( $p<0.05$; Student's $t$ test). $\boldsymbol{E}$, The results from $\boldsymbol{D}$ are superimposed on the results of untreated Gdx rats $(\bigcirc)$ and sham rats $(\mathbf{O}$; data from Fig. 3). There were no significant differences in LTP between DHT-treated slices and untreated sham controls ( $p>0.05$; Student's $t$ test). $\boldsymbol{F}$, The first minutes after LTP induction in $\boldsymbol{D}$ and $\boldsymbol{E}$ are expanded for slices from $\mathbf{G d x}$ rats treated with DHT (blue circles) and Gdx rats treated with vehicle (red circles). The differences were significant: ${ }^{*} p<0.05$ (asterisk beside the vertical bar, two-way RM-ANOVA; asterisks above the symbols, post hoc tests).

the maximal recurrent fEPSP were not different either (Gdx: $5.02 \pm 0.11$; sham: $5.05 \pm 0.13$; Student's $t$ test, $p=0.852$ ).

PPF of the recurrent fEPSP slope (half-maximal stimulus, 40 $\mathrm{ms}$ interstimulus interval) was significantly greater in Gdx rats $(120.7 \pm 6.7 \%, n=15$ slices, 11 rats; sham: $98.3 \pm 7.0 \% ; n=10$ slices, 9 rats; $p=0.034)$.

DHT sensitivity of MF transmission and plasticity in Gdx rats $M F$ fEPSPs of $G d x$ rats are reduced by $D H T$

Testosterone is metabolized in the brain to DHT, a potent agonist at the androgen receptors, which are present in MFs of the adult male rat (Tabori et al., 2005). Therefore, we determined whether a deficiency in DHT was the reason for the differences in MF transmission between Gdx and sham rats. We also determined whether one of the metabolites of DHT, Adiol, would have effects on MF fEPSPs because several studies suggest a potent effect of Adiol to enhance the actions of GABA at $\mathrm{GABA}_{\mathrm{A}}$ receptors (Frye et al., 2001; Edinger et al., 2004; Frye and Edinger, 2004; Frye et al., 2004; Reddy, 2004a,b; Edinger and Frye, 2005; Kaminski et al., 2005; Frye et al., 2010; Reddy and Jian, 2010).

MF stimulation in normal ACSF was initially tested for a 10 min baseline period to confirm that fEPSP slope was stable (Fig. $5 A 1)$. Then slices were exposed to vehicle $(0.0005 \%$ ethanol in ACSF), and the responses that were recorded 30 min later were compared with the baseline to confirm that vehicle had no detectable effect. Next, slices were exposed for $30 \mathrm{~min}$ to Adiol at a concentration that induced near-maximal potentiation of $\mathrm{GABA}_{\mathrm{A}}$ receptors in whole-cell recordings from CA1 pyramidal neurons (50 nM) (Reddy and Jian, 2010). Afterward, ACSF containing $50 \mathrm{~nm}$ DHT was applied for $30 \mathrm{~min}$.

As shown in Fig. 5A2, MF fEPSPs of Gdx rats declined during exposure to DHT. One-way RM-ANOVA in Gdx rats showed that there was a significant change in fEPSP slope during the experiment $\left(F_{(3,15)}=21.786 ; p<0.001\right)$ with fEPSP slope decreasing to $72.3 \pm 3.2 \%$ of control after DHT, significantly different from responses recorded before DHT (paired $t$ test, $p=$ $0.017)$. However, there were no significant effects of vehicle or Adiol (paired $t$ tests, $p>0.05$ ). In sham rats, there was no effect of either DHT or Adiol (one-way RM-ANOVA; $F_{(3,11)}=0.316 ; p=$ 0.814; Fig. 5B).

These experiments suggested that DHT decreased MF transmission but Adiol did not. However, the effect of DHT could have resulted in part from pretreatment with Adiol because Adiol can be converted back to DHT in the brain (Chetyrkin et al., 2001). It is also possible that altering GABAergic transmission by preexposure to Adiol might affect subsequent responses to DHT, even though Adiol by itself had no measurable effect. To test this possibility, slices from Gdx rats were treated with $50 \mathrm{~nm}$ DHT immediately after the baseline (Fig. 5B1). DHT reduced the slope of the fEPSP to $74.8 \pm 5.6 \%$ of control ( $n=5$ slices, 5 rats; paired $t$ test, $p=0.004$; Fig. 5B2). In contrast, there were no effects of Adiol after it was added (immediately after the baseline; $n=3$ slices, 3 rats; Fig. 5C1,C2), and there was no significant effect of DHT in slices from sham controls $(n=4$ slices, 4 rats; paired $t$ test, $p=0.384$; data not shown). 
A

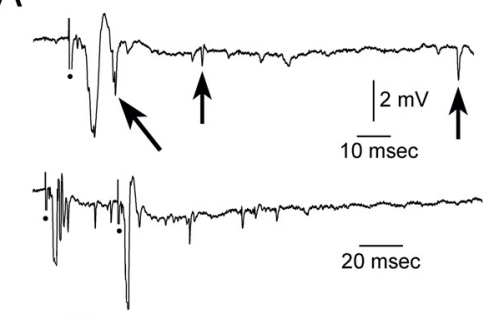

D1

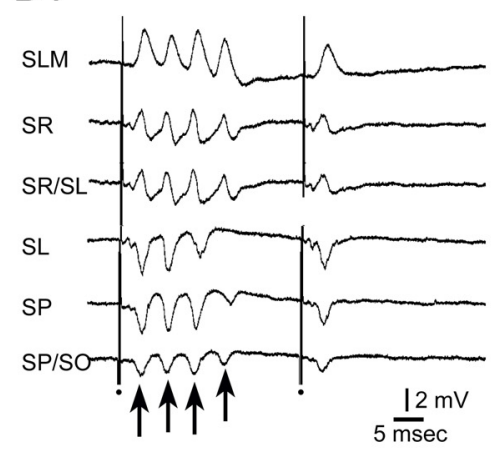

B

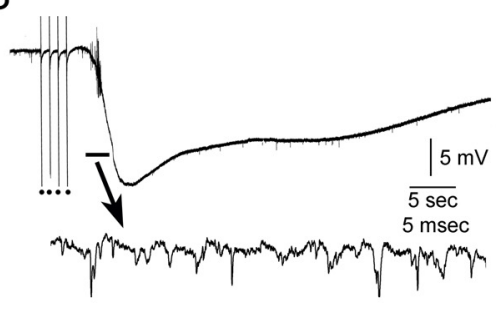

2

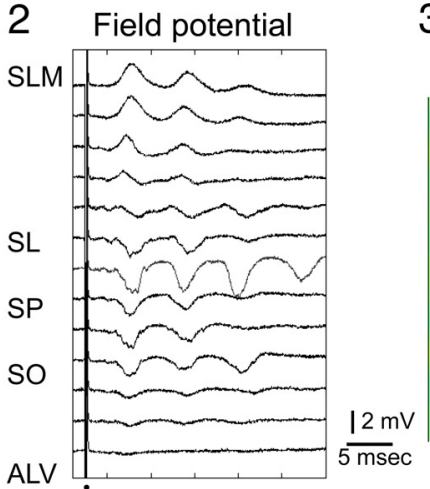

C

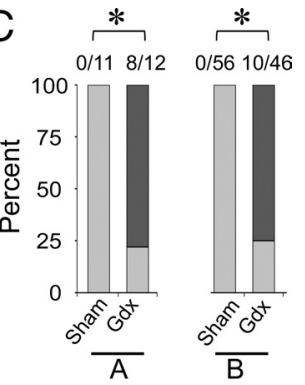

$3 \operatorname{CSD}$

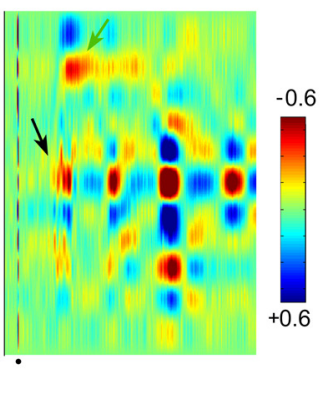

Figure 6. Increased excitability in area CA3 of Gdx rats. $A$, An example of a response to MF stimulation in a slice from a Gdx rat, recorded in stratum pyramidale, shows that more than one population spike (angled arrow) was elicited by a single stimulus, an indication of increased excitability. In addition, spontaneous activity was higher than normal (vertical arrows indicate unit activity and spontaneous field potentials). $\boldsymbol{B}$, Top, An example of an SD episode in a slice from a Gdx rat. Repetitive MF stimuli (half-maximal stimuli in pairs with 40 ms interstimulus intervals at 1 $\mathrm{Hz}$ for a total of 8 stimuli in 4 s) induced SD. In other slices, TBS elicited SD (see $\boldsymbol{C}$ ). Bottom: The part of the SD episode marked by the horizontal bar is expanded to show the increase in spontaneous activity at the onset of SD. $C$, Incidence of hyperexcitability in slices from $\mathrm{Gdx}$ rats is shown. Left (corresponding to $A$ ), More than one field potential per MF stimulus occurred in 0 of 56 slices from sham rats and 10 of 46 slices (22\%) from Gdx rats. Right (corresponding to B), SD episodes were evoked by TBS stimulation in 0 of 11 slices from sham rats and 8 of 12 (75\%) of slices from Gdx rats, which was a significant difference: ${ }^{*} p<0.05$ ( $\chi^{2}$ test for A; Fisher's test for B). $\boldsymbol{D}$, Rhythmic, repetitive field potentials in a subset of slices from Gdx rats. D1, A fixed stimulus to the MFs was used to examine responses in all layers of area CA3b. The number of repetitive field potentials (arrows) was similar regardless of the layer. The largest fEPSP occurred in stratum lucidum with reversal of polarity in stratum lacunosum-moleculare. A second stimulus triggered $40 \mathrm{~ms}$ after the first only elicited one field potential. D2, D3, CSD analysis of the response to the first stimulus illustrates the stereotypical nature of repetitive field potentials and their ability to induce abnormal sinks and sources throughout area CA3. An arrow points to the sink with shortest latency, in stratum lucidum. Calibration: +0.6 to $-0.6 \mathrm{mV} / \mathrm{mm}^{2}$.

To confirm that DHT had effects on MF-evoked population spikes, and also that DHT inhibited MF transmission at multiple stimulus strengths, recordings were made in the pyramidal cell layer of Gdx rats in response to three intensities of MF stimulation: $\sim 30 \%, 50 \%$, and $100 \%$ of the maximum. Comparisons were made between baseline and $30 \mathrm{~min}$ after the onset of treatment (vehicle, $n=4$ slices, 4 rats; DHT, $n=4$ slices, 4 rats). There was a significant effect of DHT (RM-ANOVA; $F_{(1,12)}=40.17$; $p<0.001)$, with amplitudes lower after DHT exposure at all stimulus intensities (Bonferroni's tests, $p<0.05$ ). There was a significant interaction between stimulus strength and treatment $\left(F_{(2,12)}=8.72 ; p=0.005\right)$.

In summary, DHT reduced fEPSPs in Gdx rats, but Adiol did not, and there were no significant effects of any of the steroids in slices from sham controls. The results suggest that an androgen receptorsensitive component of MF transmission emerges after Gdx.

\section{MF LTP in $G d x$ rats is reduced by DHT}

Because a DHT-sensitive component of synaptic transmission emerged after Gdx, we tested the DHT dependence of LTP in Gdx rats. After a $15 \mathrm{~min}$ baseline period, slices were exposed to $50 \mathrm{~nm}$ DHT or vehicle (Fig. 5D). LTP was induced 15 min later, the time when DHT began to exert its effects in the experiments described above. In slices where the fEPSPs declined within $15 \mathrm{~min}$, an adjustment in stimulus intensity was made so that the train used to induce LTP would be half-maximal. Exposure to DHT continued until 15 min after LTP induction, and then drug-free buffer was used for the remainder of the experiment. LTP was reduced in DHT-treated slices compared with slices from Gdx rats treated with vehicle (Gdx + DHT, $85.5 \pm 10.1 \%$; Gdx + vehicle, $135.1 \pm$ 13.1\%; Student's $t$ test; $p=0.020$; Fig. $5 D$ ).

Figure $5 E$ compares LTP in slices from Gdx rats that were preexposed to DHT before LTP was tested, Gdx rats pretreated with vehicle, slices from Gdx rats that had no pretreatment, and slices from sham rats that were untreated. LTP in DHT-treated slices from Gdx rats was comparable with LTP in slices of untreated sham rats (Student's $t$ test, $p=0.475$ ); LTP in vehicletreated slices of $\mathrm{Gdx}$ rats was similar to untreated slices of $\mathrm{Gdx}$ rats (Student's $t$ test, $p=0.565$ ).

PTP was also reduced by DHT (Fig. 5E). Compared with vehicle-treated slices, fEPSP slopes in the first 3 min after LTP induction were significantly reduced by DHT (two-way $\operatorname{RM}-\operatorname{ANOVA}\left(F_{(1,45)}=5.291 ; p=0.047\right.$; Fig. $\left.5 F\right)$.

In summary, a DHT-sensitive component of MF PTP and LTP was present in slices from Gdx rats. Sham rats did not exhibit LTP, so the DHT-sensitive component of PTP and LTP was only evident in Gdx rats.

\section{Hyperexcitability in $\mathrm{Gdx}$ rats}

While recording in the pyramidal cell layer of Gdx rats, increased excitability was detected in a subset of slices (Fig. 6). The increase in excitability was manifested in several ways. For example, a single MF stimulus could evoke $>1$ population spike, whereas in sham rats there was only one population spike/stimulus. Also, there were small $(\sim 1 \mathrm{mV})$ spontaneous field potentials in slices of 
Gdx rats when recordings were made in the pyramidal cell layer, and more unit activity than sham rats (Fig. 6A).

Another sign of abnormal excitability in slices from Gdx rats was SD in response to repetitive MF stimulation (Fig. 6B). When SD followed TBS stimulation of the MFs, it did so rapidly (within seconds; Fig. 6B). SD episodes were stereotypical: they were composed of an initial phase where small $(\sim 1 \mathrm{mV})$ spontaneous population spikes occurred and a second phase where there was a negative shift in the DC potential, which peaked at -14 to -16 $\mathrm{mV}$ within $\sim 15 \mathrm{~s}$ of the onset of spontaneous activity (Fig. $6 B$ ). Subsequently, there was a recovery of the DC potential within $\sim 5$ min (Fig. 6B). During the recovery, no response to MF stimulation could be elicited even in response to the highest stimulus strength.

The first type of hyperexcitability, where $>1$ population spike per stimulus occurred, was found in 10 of $45(22 \%)$ slices from 20 Gdx rats and 0 of 56 slices in 24 sham rats $\left(\chi^{2}\right.$ test, $p<0.001$; Fig. $6 C)$. SD after TBS stimulation occurred in 8 of $12(75 \%)$ slices from $5 \mathrm{Gdx}$ rats and 0 of 11 slices in 5 sham rats (Fisher's exact test, $p=0.001$; Fig. $6 C$ ). Four of the 8 slices from Gdx rats that exhibited SD also showed more than one population spike/MF stimulus.

Another indication of abnormal excitability is shown in Figure $6 \mathrm{D} 1$. In this case, field potentials were repetitive but at a rhythm that was slower $(\sim 20 \mathrm{~Hz})$ than the multiple population spikes in Figure 6A. CSD analysis (Fig. 6D2,D3) showed the stereotypical nature of the rhythmic field potentials across laminae of CA3 and that the earliest sink was in stratum lucidum (Fig. $6 D 2, D 3$, arrow), suggesting the MF pathway initiated activity. Five of $45(11 \%)$ slices from Gdx rats exhibited the rhythmic field potentials shown in Figure $6 C, D$; these were not the same slices that showed other signs of increased excitability in Figure $6 A, B$. Therefore, the total number of slices exhibiting hyperexcitability of one type or another was 19 of 45 , or $42 \%$.

The abnormal excitability that was recorded in Gdx rats was similar to the effects of recombinant BDNF superfused onto slices of normal adult male rats (Scharfman, 1997) and the responses to MF stimulation in rodents with elevated BDNF protein levels (Croll et al., 1999; Scharfman et al., 2003, 2007), which were blocked by the Trk receptor antagonist K252a (Scharfman, 1997; Scharfman et al., 2003, 2007). Therefore, we determined whether K252a would reduce excitability in Gdx rats.

As shown in Figure 7A, K252a reduced the first type of abnormal excitability in Gdx rats ( $>1$ population spike/MF stimulus; Fig. 6A). Specifically, perfusion of slices with $300 \mathrm{~nm}$ K252a for 15 min blocked the second population spike that was elicited by MF stimulation ( $n=3$ slices, 2 rats; Fig. $7 A)$, and vehicle $(0.003 \%$ DMSO) had no effect (2 slices from 2 other rats; data not shown). In slices where repetitive field potentials were elicited by a single stimulus (e.g., Fig. 6D), an input-output curve for the amplitude of the first field potential was generated before and after exposure to K252a (Fig. 7B1-B3). There was a significant effect of K252a (two-way RM-ANOVA; $F_{(1,20)}=87.483 ; p<0.001$ ) and an interaction $\left(F_{(5,20)}=15.129 ; p<0.001\right)$ with significant differences at all intensities above the minimum (where evoked potentials were negligible in all conditions; Student's $t$ test, $p<0.05$; Fig. $7 B 1-B 3$ ). There was no effect of vehicle (pre vs post vehicle, twoway RM-ANOVA; $F_{(5,20)}=0.188 ; p=0.687$; Fig. $7 B 3$ ).

To evaluate the effect of K252a on SD, SD was elicited by stimulus trains $(1 \mathrm{~Hz}$, paired pulses for $10 \mathrm{~s})$ as described previously (Scharfman, 1997; Scharfman et al., 2003, 2007), which were triggered once every 15 min (Fig. 7C,D; K252a: $n=3$ slices, $3 \mathrm{Gdx}$ rats; vehicle: $n=3$ slices, 3 other Gdx rats). After a $30 \mathrm{~min}$ baseline period, K252a was added to the ACSF for $15 \mathrm{~min}$, followed by drug-free buffer (Fig. 7C,D). There was a significant effect of K252a on the amplitude of SD episodes (measured from baseline to the peak of the SD episode; one-way RM-ANOVA; $\left.F_{(9,29)}=14.268 ; p<0.001\right)$ at 15 and 30 min after K252a was added (paired $t$ test, $p=0.033$ and $p=0.031$, respectively; Fig. 7D2). There were no detectable effects of vehicle (one-way RM-ANOVA; $F_{(9,29)}=1.049 ; p=0.442 ;$ Fig. 7D2).Together, the results suggested that a subset of Gdx rats exhibited hyperexcitability that was dependent on Trk receptors.

\section{BDNF protein expression increases in MFs after Gdx}

Increased excitability in Gdx rats (Figs. 6 and 7) was similar to rats or mice with elevation of BDNF levels in MFs (Croll et al., 1999; Scharfman et al., 2003, 2007). Therefore, we determined whether MF BDNF levels were increased in Gdx rats.

Initial experiments used a well-described polyclonal antibody to BDNF (Conner et al., 1997; Yan et al., 1997) and showed that Gdx rats (which had surgery at $\sim 60 \mathrm{~d}$ of age and were evaluated $\sim 2$ weeks later) exhibited greater BDNF-ir in the MFs than sham rats (Fig. 8A1-A2).

Similar results were obtained using a second antibody (monoclonal; Fig. $8 B-D$ ). Using the second antibody, 5 immunocytochemical procedures were conducted. For each procedure, a Gdx and sham littermate were subjected to surgery on the same day, at $\sim 60 \mathrm{~d}$ of age ( $61.9 \pm 2.0 \mathrm{~d}, n=5$ /group) followed by perfusionfixation on the same day after surgery $(12.0 \pm 0.6 \mathrm{~d})$, and brains were processed together. Sections from the 10 rats were quantified and analyzed in pairs (Gdx and sham). The location where the MF terminal plexus ends (Fig. 9H1) was used for quantification because BDNF-ir was always greatest there, regardless of surgical pretreatment (Fig. $8 D$ ). The timeline of the experiments is shown in Figure 8E1, and the results shown in Figure 8E2 demonstrated that MF BDNF-ir was greater in Gdx rats (Student's $t$ test, $p=0.001$ ).

A second experiment was conducted to determine whether the increase in BDNF protein in MFs in Gdx rats was long-lasting (Fig. $8 F$ ). For this purpose, rats were perfusion-fixed 2 months instead of 2 weeks after surgery (Fig. 8F1). Again, surgery was conducted in pairs, so the age at surgery was the same (59.8 \pm $1.0 \mathrm{~d}$ ) and delays between surgery and perfusion were the same $(61.2 \pm 1.9 \mathrm{~d}, n=5$ /group). As shown in Figure 8F2, Gdx rats exhibited greater MF BDNF-ir than sham controls (Student's $t$ test, $p=0.002$ ). Therefore, the increase in MF BDNF-ir after Gdx appeared to be robust and long-lasting.

\section{Gdx rats exhibit MF sprouting}

As recordings in stratum pyramidale and stratum oriens were conducted, it became clear that Gdx rats often exhibited fiber volleys and fEPSPs in these layers in response to MF stimulation (Fig. 9A), leading to diverse sinks in these layers using CSD analysis (Fig. 9B). These observations, and the results discussed above showing that BDNF-ir in MFs was elevated after Gdx, suggested that there was sprouting of MF axons into the pyramidal cell layer and stratum oriens of Gdx rats (diagrammed schematically in Fig. $9 A)$. Sprouting could be a response to increased BDNF levels in MFs because BDNF application to the MFs has been suggested to induce MF axon outgrowth (Lowenstein and Arsenault, 1996; Tamura et al., 2006; Gomez-Palacio-Schjetnan and Escobar, 2008; Tamura et al., 2009), although all studies do not agree (Bender et al., 1998; Qiao et al., 2001; Shetty et al., 2003).

We determined whether MF sprouting into stratum oriens occurred using dynorphin B as a marker of the MFs (Pierce et al., 


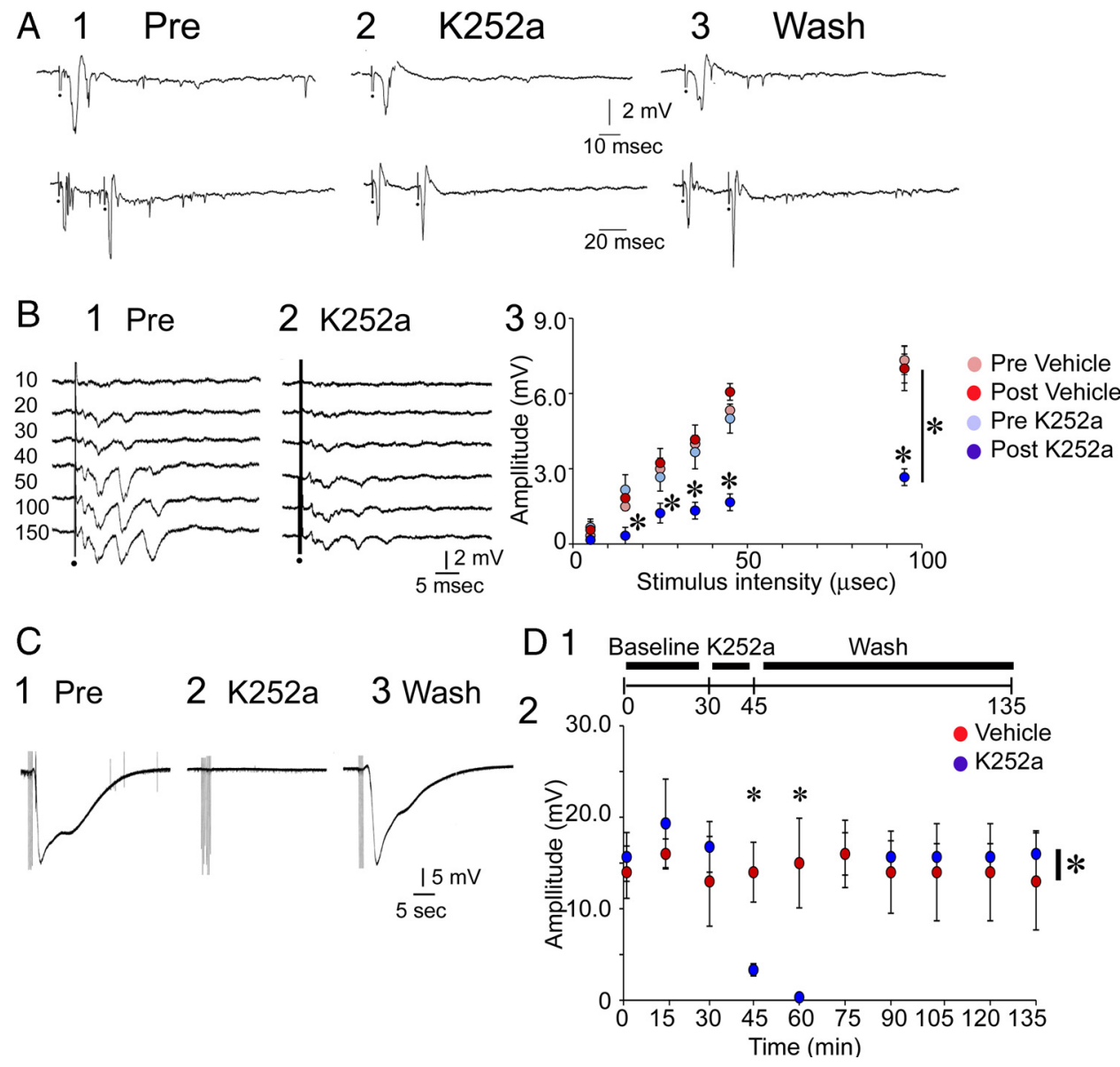

Figure 7. K252a reduces excitability in slices from Gdx rats. A1, The response to MF stimulation is shown before $300 \mathrm{~nm} \mathrm{K252a}$ was added to the ACSF. Same slices as Figure $6 A$. A2, The response to the same stimulus is shown $45 \mathrm{~min}$ later. The population spikes evoked by the stimulus, especially the secondary population spikes, were reduced by K252a. Spontaneous activity was also reduced. A3, There was a partial reversal after K252a-containing ACSF was replaced by drug-free buffer for $60 \mathrm{~min}$. B1, B2, K252a was perfused onto a different slice from a Gdx rat where rhythmic, repetitive field potentials were evoked (same slice as Fig. 6D). Several stimulus strengths (10-150 $\mu$ s) were used before (1, Pre) and after K252a application (10-150 $\mu$ s; 2, K252a). K252a reduced the amplitude of evoked responses. $\mathbf{B}$, The amplitude of the first fEPSP recorded in stratum lucidum is shown for all stimulus intensities. In addition, data from slices treated with vehicle are shown. There was a significant effect of K252a (comparison of pre-K252a and 30 min after K252a (light blue and dark blue circles): ${ }^{*} p<0.05$ (two-way RM-ANOVA followed by posthoctests), but there were no effects of vehicle (comparison of pre-DMSO and 30 min after DMSO; light red and dark red circles; $p>0.05$; two-way RM-ANOVA). C, K252a blocked SD episodes reversibly. C1, An example of an SD episode in response to repetitive MF stimulation (2 half-maximal stimuli $40 \mathrm{~ms}$ apart at $1 \mathrm{~Hz}$ for $10 \mathrm{~s}$ ) is shown before adding $300 \mathrm{~nm} \mathrm{K252a}$ to the buffer. (2, After K252a, the same stimulation did not evoke SD. C3, Sixty minutes after drug-free buffer was resumed, stimulation evoked SD. D1, A timeline of the experiments is shown. MF stimulation (the same stimulus train as in C1-C3) was triggered at $15 \mathrm{~min}$ intervals during a baseline, followed by exposure to $300 \mathrm{~nm} \mathrm{K252a} \mathrm{(or} \mathrm{vehicle)} \mathrm{for} 15 \mathrm{~min}$, and drug-free ACSF at the end. D2, A comparison of the effects of vehicle and K252a on the amplitude of SD episodes evoked by repetitive $1 \mathrm{~Hz}$ MF stimulation in slices from Gdx rats ( $n=3$ slices, 3 rats/treatment). Two-way RM-ANOVA showed that there was a significant effect of K252a compared with vehicle: * $p<0.05$ (asterisk by the vertical bar; one-way RM-ANOVA followed by post hoc tests) and a significant effect of K252a 15 and 30 min after the start of K252a application: ${ }^{*} p<0.05$ (asterisks above symbols).

1999). Immunocytochemical comparisons were made between Gdx and sham rats ( $n=7$ /group) that were perfused $\sim 2$ weeks after surgery $(15.5 \pm 2.7 \mathrm{~d}$ for each group). Animals were perfused and processed in pairs, with one Gdx and one sham rat subjected to surgery on the same day, perfused the same day, cut the same day, with identical delays between surgery and perfusion, and were processed at the same time (similar to the experiments discussed above for BDNF-ir). As shown in Figure $9 C-F$, Gdx rats exhibited a band of dynorphin-ir in stratum oriens of $\mathrm{CA} 3 \mathrm{a} / \mathrm{b}$, which was not evident in sham rats.

To quantify the differences in dynorphin-ir in Gdx rats compared with sham controls, a ROI was drawn around stratum lucidum, pyramidale and oriens to encompass the area where dynorphin-ir was most robust in Gdx rats (Fig. 9G1). Then the mean grayscale value was determined for that ROI, placing the same ROI over each section from each rat so that it covered stratum lucidum, stratum pyramidale, and stratum oriens of CA3a/b (Fig. 9G1). Next, the ROI was moved to stratum radia- tum (Fig. 9G1) where background staining was estimated, and subtracted from the first measurement. The results showed that the mean grayscale value for each Gdx rat was greater than the sham rat that was processed with it (paired $t$ test, $p=0.010$; Fig. 9G2).

An additional measurement was also made within the terminal plexus of the MF pathway in stratum lucidum near CA3 (Fig. 9H1) to address the possibility that dynorphin-ir in the normal MF pathway increased after Gdx. As shown in Figure 9H2, there were no significant differences in dynorphin-ir (Student's $t$ test, $p=0.487$ ). Therefore, an increase in dynorphin expression in $\mathrm{Gdx}$ rats does not explain the increased dynorphin-ir in stratum oriens of Gdx rats in Figure $9 C-G$. Instead, the results suggest that new MFs developed in Gdx rats in stratum oriens.

Collectively, the data suggest that Gdx rats exhibit MF sprouting $\sim 2$ weeks after surgery. There appeared to be a functional effect of the sprouted fibers because fEPSPs evoked by MF stimulation could be recorded throughout stratum lucidum, stratum pyramidale, and stratum oriens of Gdx rats. 
A

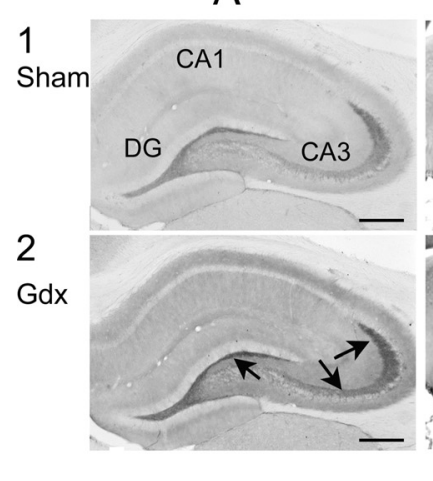

B

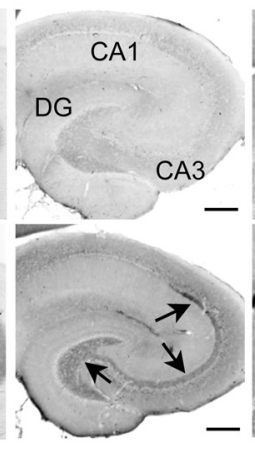

C

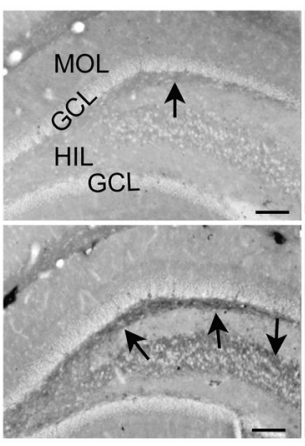

$\mathrm{D}$

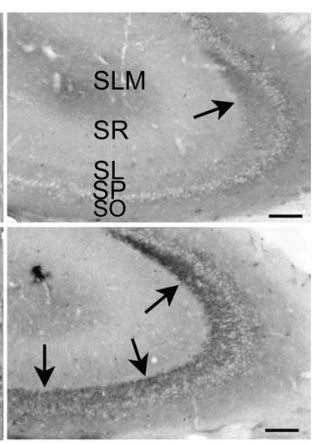

2

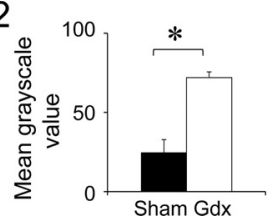

Figure 8. Gdx rats exhibit increased BDNF-ir in the MF pathway. $\boldsymbol{A}, \mathrm{BDNF}$-ir in a sham ( $\boldsymbol{A} \mathbf{1})$ and $\mathrm{Gdx}$ rat (A2) using a rabbit polyclonal antibody to BDNF (provided by Amgen-Regeneron partners). DG, Dentate gyrus. Arrows point to the MF pathway. Scale bar, $500 \mu \mathrm{m}$. B, BDNF-ir in a different sham (B1) and Gdx (B2) rat using a different antibody (mouse monoclonal; Sigma-Aldrich). Scale bar, $500 \mu \mathrm{m}$. C, Higher magnification of a coronal section from the same animals as in $\boldsymbol{B}$. There was greater BDNF-ir in the MFs (arrows) of the Gdx rat. MOL, Molecular layer; $G C L$, granule cell layer; HIL, hilus. Scale bar, $100 \mu \mathrm{m}$. D, Area CA3 of the same sections used in ( show MF staining (arrows) that is darker in the Gdx rat. Scale bar, $100 \mu \mathrm{m}$. E1, A timeline is shown for experiments where rats were subjected to surgery at $\sim 60 \mathrm{~d}$ of age and perfusion-fixed $\sim 2$ weeks later. E2, Mean grayscale values (measured as described in Fig. $9 \mathrm{H} 1$ ). Sections from $\mathrm{Gdx}$ rats exhibited greater values than sham rats: ${ }^{*} p<0.05$ (Student's $t$ test). $\mathbf{F 1}$, The timeline is shown for experiments where rats had surgery at $\sim 60 \mathrm{~d}$ of age and were perfused $\sim 2$ months later. $\boldsymbol{F 2}$, Sections from Gdx rats had greater values than sham rats: ${ }^{*} p<0.05$ (Student's $t$ test).

A 1 sham

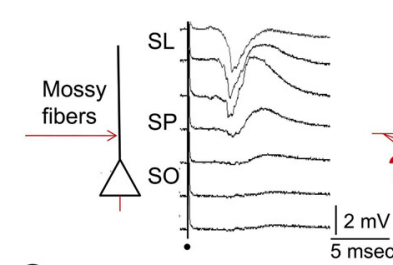

C D

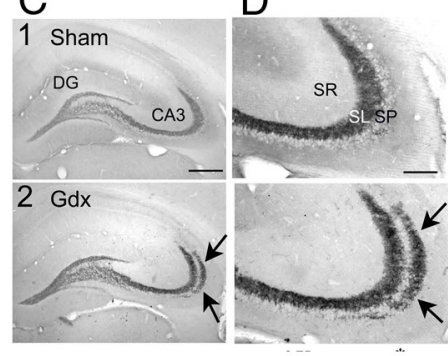

$2 \mathrm{Gdx}$

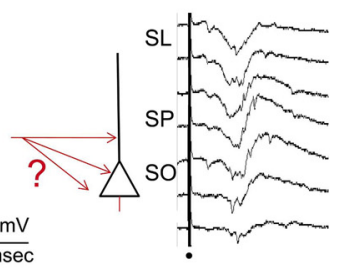

E<smiles>[BH3-]</smiles>

F

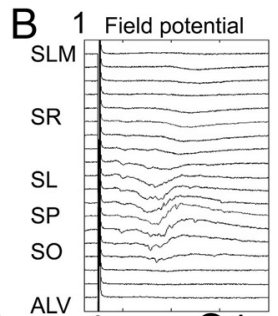

G1

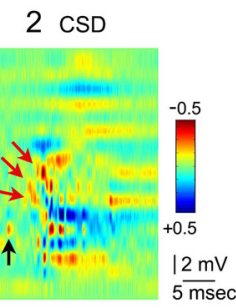

$\mathrm{H} 1$
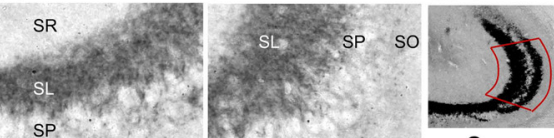

2
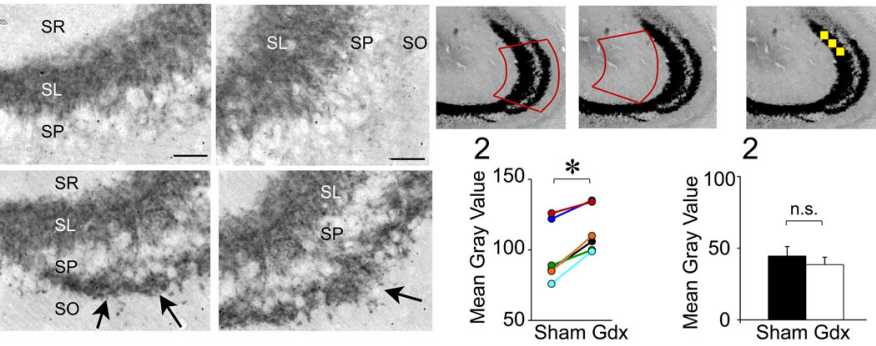

Figure 9. Gdx in adult male rats leads to MF sprouting in stratum oriens of CA3a/b. A1, Left, A schematic illustrates the MF pathway (red) in a sham rat. Right, Representative responses to a fixed MF stimulus are shown for a slice of a sham rat. A1, A2, Only those responses between stratum lucidum and stratum oriens are shown. A2, Left, An illustration of the MF pathway in a Gdx rat where MFs may sprout into stratum oriens (red arrows with question mark). Right, Responses of a slice from a Gdx rat recorded in a similar manner to A1. Responses are similar in stratum lucidum, pyramidale, and oriens and appear to be fEPSPS. B, All field potentials (B1) and CSD (B2) are shown for the Gdx rat in $\boldsymbol{A 2}$. Red arrows point to current sinks in or near stratum lucidum. The black arrow corresponds to a fiber volley in stratum oriens, suggesting that MF axons were present in stratum oriens. $\mathbf{C}-\boldsymbol{F}$, Dynorphin-ir in a sham (1) and Gdx (2) rat. D-F, Arrows point to the area of stratum oriens where dynorphin-ir is evident in the Gdx rat but not the sham rat. DG, Dentate gyrus; $\mathrm{SR}$, stratum radiatum; $\mathrm{SL}$, stratum lucidum; $\mathrm{SP}$, stratum pyramidale; $\mathrm{SO}$, stratum oriens. Scale bar: $C, 500$ $\mu \mathrm{m} ; \boldsymbol{D}, 100 \mu \mathrm{m} ; \boldsymbol{E}, \boldsymbol{F}, 25 \mu \mathrm{m} . \mathbf{G 1}$, Left, The template (red) that was used to measure dynorphin-ir in CA3 is shown. Right, To estimate background staining, the template was positioned over stratum radiatum as shown. For each section, the mean grayscale value for the background was subtracted from the mean grayscale value of the first measurement. G2, Animals were prepared in pairs (same surgery date, same perfusion date, immunocytochemical processing at the same time), and results are shown for each pair (left, sham; right, Gdx). The Gdx rats exhibited a greater mean grayscale value: ${ }^{*} p<0.05$ (paired $t$ test). $\boldsymbol{H 1}$, The yellow box that was used to determine mean grayscale values of the terminal field of MFs is shown. Three measurements within the area of the terminal plexus, depicted by three boxes, were averaged for each section. Three measurements in stratum radiatum were also made, to estimate background staining, and the mean of these measurements was subtracted from the mean of the stratum lucidum measurements for $\mathbf{H 2}$. $\mathbf{H 2}$, The mean grayscale value was similar in sham and Gdx rats (not significant [n.s.]; $p>0.05 ;$; paired $t$ test). The results suggest that dynorphin-ir in stratum oriens of Gdx rats was the result of new dynorphin-ir fibers, not increased dynorphin-ir in preexisting fibers. 


\section{A Trk-dependent component of MF transmission and LTP emerges after Gdx \\ $M F$ transmission in $G d x$ rats is reduced by K252a}

Because the hyperexcitability in slices of Gdx rats was sensitive to $\mathrm{K} 252 \mathrm{a}$ and BDNF protein was increased in MFs, we asked whether the increase in MF transmission and synaptic plasticity of Gdx rats would be K252a-sensitive. As shown in Figure $10 A 1$, slices from $\mathrm{Gdx}$ and sham rats ( $n=4$ slices from 4 rats/group) were recorded for a $15 \mathrm{~min}$ baseline period, exposed to vehicle ( $0.003 \%$ DMSO), and the responses that were recorded 30 min later were compared with the baseline. Next, slices were exposed to $300 \mathrm{nM} \mathrm{K} 252 \mathrm{a}$ for $30 \mathrm{~min}$, and subsequently slices were perfused with drug-free buffer for $30 \mathrm{~min}$ to determine whether effects of K252a were reversible.

Drug effects were evaluated by twoway RM-ANOVA. There was a significant effect of surgical pretreatment (Gdx or sham; $\left.F_{(1,18)}=28.092 ; p=0.002\right)$ and a significant interaction between the surgical pretreatment and responses to drug treatments $\left(F_{(3,18)}=6.995 ; p=0.003\right.$; Fig. $10 A 2)$. The slope of fEPSPs in Gdx rats decreased in response to $\mathrm{K} 252 \mathrm{a}$ (one-way RM-ANOVA; $F_{(3,15)}=6.848 ; p=0.006$; Student's $t$ test, $p=0.013$ ) to $61.0 \pm 5.8 \%$ of control (Fig. 10A2). There was no significant effect of $\mathrm{K} 252 \mathrm{a}$ in sham controls (one-way RM-ANOVA; $F_{(3,15)}=0.098$; Student's $t$ test, $p=0.965$; Fig. 10A2).

There was variable recovery after resuming drug-free buffer (Fig. 10A2; wash, $\bigcirc$ with large SEM), unlike shorter periods of K252a application in previous experiments where recovery was more consistent (Fig. 7; similar SE bars during the experiments). These data suggested that prolonged exposure to dilute DMSO, first as the vehicle pretreatment and then as the K252a solvent, had adverse effects, leading to inability of some slices to recover during wash. Therefore we also evaluated K252a in slices without pretreatment with dilute DMSO $(n=8$ slices, $8 \mathrm{Gdx}$ rats; Fig. 10B1). As shown in Figure 10B2, K252a depressed the fEPSP slope, and there was more consistent recovery. Together, these data suggest that a Trk-sensitive component of MF transmission emerged after Gdx that was not normally present in sham rats.

\section{MF LTP in Gdx rats is reduced by K252a}

To test the effect of K252a on LTP, a 15-min-long baseline was followed by exposure to $300 \mathrm{nM} \mathrm{K252a}$ for $15 \mathrm{~min}$, the latency when K252a began to exert an effect in Figure 10B. After LTP induction, K252a exposure continued for another $15 \mathrm{~min}$, followed by perfusion with drug-free buffer (Fig. 10C). For comparison, slices were exposed to vehicle for $15 \mathrm{~min}$ before and after LTP induction (Fig. 10C).

K252a-treated slices had less LTP than vehicle-treated slices: $60 \mathrm{~min}$ after LTP induction, fEPSP slopes in K252a-treated slices were $62.8 \pm 17.1 \%$ of control ( $n=6$ slices, $6 \mathrm{Gdx}$ rats; Fig. $10 C$ ), whereas vehicle-treated slices exhibited $113.7 \pm 12.7 \%$ potentia- tion ( $n=7$ slices, 7 Gdx rats), which were significantly different (Student's $t$ test; $p=0.031$ ). K252a-treated slices of Gdx rats were not significantly different from slices of sham rats that were untreated (Student's $t$ test, $p=0.439$ ), suggesting that K252a reversed the effect of Gdx (Fig. 10C).

K252a-treated slices from Gdx rats also showed decreased PTP relative to vehicle-treated slices; two-way RM-ANOVA showed that there was an interaction between treatment (K252a vs vehicle) and $\operatorname{PTP}\left(F_{(9,99)}=2.441 ; p=0.015\right)$ with K252atreated slices showing significantly decreased PTP immediately after LTP induction (Student's $t$ test, $p=0.006$ ) and at $2 \mathrm{~min}$ ( $p=0.017)$, but not other times.

These data were consistent with the hypothesis that a Trksensitive component of synaptic plasticity emerged after Gdx. However, LTP in vehicle-treated slices was reduced compared with untreated slices of Gdx rats $(p=0.036$; Fig. $10 C)$, suggesting an adverse effect of vehicle. An effect of vehicle was also suspected based on data in Figure 10A2 where there was inconsistent recovery after prolonged application of vehicle (exposure to vehicle alone, then K252a dissolved in vehicle). Therefore, we also tested the effect of a scavenger of BDNF, TrkB-IgG, where vehicle was $0.9 \% \mathrm{NaCl}$. TrkB-IgG-protein is composed of the recognition site of TrkB and the FC region of human IgG1 (Binder et al., 1999). Comparison was to human IgG1. The concentration of TrkB was chosen because of its efficacy in previous studies (Kang et al., 1996; Skucas et al., 2011). 
As shown in Figure 10D, TrkB-IgG suppressed LTP compared with IgG. TrkB-IgG-treated slices exhibited $112.4 \pm 12.0 \%$ potentiation at $60 \mathrm{~min}$ after LTP induction ( $n=7$ slices, $6 \mathrm{Gdx}$ rats), compared with $141.7 \pm 6.9 \%$ potentiation in IgG-treated slices ( $n=9$ slices, $6 \mathrm{Gdx}$ rats; Student's $t$ test, $p=0.030$ ). LTP in IgG-treated slices of Gdx rats was not significantly different from untreated slices of Gdx rats (Student's $t$ test, $p=0.674$ ). PTP was reduced by TrkB-IgG compared with IgG: 1 min after LTP induction, PTP was $191.4 \pm 15.7 \%$ in TrkB-IgG treated slices and $251.7 \pm 21.6 \%$ in IgG-treated slices (Student's $t$ test, $p=0.036$ ).

Together, these data suggest that a Trk-sensitive component of MF PTP and LTP emerged after Gdx.

\section{Discussion}

The results show that MF transmission, excitability, and plasticity in area CA3 increase after Gdx in adult male rats. The mechanisms involve an increase in androgen receptor-dependent and Trk-dependent signaling. The results are relevant to sex differences in hippocampus, and clarifying the role of androgens in hippocampal function. With a few exceptions (Mizoguchi et al., 1992; Isgor and Sengelaub, 2003; Kaminski et al., 2005; Hatanaka et al., 2009), information about the effects of androgens in area CA3 is particularly limited. The results are also relevant to conditions when circulating androgens are decreased, such as aging (Gooren, 2003; Yeap, 2009), and disorders where androgens have been implicated in the underlying pathophysiology (Herzog, 1991; Harden and MacLusky, 2004; Harden and MacLusky, 2005; Frye, 2006; Becker et al., 2008; Drummond et al., 2009; Etgen and Pfaff, 2009; Al Sweidi et al., 2011; Barron and Pike, 2011).

\begin{abstract}
Alterations in area CA3 after Gdx
The results show that diverse effects of Gdx occur in area CA3, including the following: (1) an increase in MF transmission, PPF, and LTP, (2) the emergence of a DHT-sensitive component of MF transmission and LTP, and (3) increased MF BDNF expression, MF sprouting, and Trk-dependent increases in MF transmission and excitability.
\end{abstract}

\section{MF transmission, $P P F$, and $L T P$}

MF transmission increased in Gdx rats because there was an increase in MF fEPSP slope and amplitude. There was an increase in fiber volley amplitude without a change in latency, suggesting an increase in axonal excitability but no change in the timing of synaptic transmission. In addition, population spike amplitude was increased in slices from Gdx rats, suggesting increased CA3 pyramidal cell output. Consistent with this finding, recurrent fEPSPs elicited by MF stimulation were increased. PPF was increased in Gdx rats, suggesting that short-term plasticity was enhanced. Short interstimulus intervals $(10-20 \mathrm{~ms})$ were unaffected, suggesting that feedback inhibition was unchanged. A neurosteroid acting on $\mathrm{GABA}_{\mathrm{A}}$ receptors (Adiol) did not reverse effects of Gdx, suggesting that disinhibition, at least at the 2 week time point after Gdx, did not cause the effects of Gdx in slices. However, the possible effects of acute depletion of Adiol in the first days after Gdx and a comprehensive study of GABAergic inhibition 2 weeks after Gdx are necessary before ruling out a role of reduced GABAergic inhibition. It is important to note that PPF was low in the control animals (relative to younger rodents; e.g., Salin et al., 1996), which we think is the result of the older ages ( $>60 \mathrm{~d}$ old) in the present study; under our recording conditions, there is greater PPF whether younger rats $(\sim 30 \mathrm{~d})$ are used $(\mathrm{H}$. E. Scharfman, unpublished data).
Using a stimulus paradigm that induces LTP in young rats (18-25 d) (Kwon and Castillo, 2008), Gdx rats exhibited robust LTP. This result suggests that long-term synaptic plasticity of the MFs was altered by Gdx. If this result can be generalized to behavior, one would predict a greater ability of the CA3 network to exhibit behavioral plasticity in Gdx rats. For example, Gdx rats might exhibit better pattern separation and completion, where the MF pathway has been suggested to play a pivotal role (Derrick, 2007; Jaffe and Gutierrez, 2007). However, Gdx rats showed a reduction in the specificity of MFs for stratum lucidum. Therefore, area CA3 of Gdx rats could exhibit a gain of function because of increased synaptic plasticity or a loss of function resulting from reduced MF specificity. Indeed, Gdx rats show both impaired and improved hippocampal function in behavioral tests (Edinger and Frye, 2004, 2007a; Frye et al., 2008; Harooni et al., 2008).

It is noteable that the Gdx rats exhibited LTP but sham controls did not. This difference could reflect greater plasticity in Gdx rats, but it also can be interpreted as a change in threshold for LTP induction. Thus, the stimulus parameters (frequency, synaptic strength) used to elicit LTP in Gdx rats may be distinct from sham controls.

\section{DHT sensitivity of MF transmission and LTP after $G d x$}

DHT exerted robust effects in slices of Gdx rats, normalizing MF fEPSPs and MF LTP as late as 2-3 weeks after Gdx. It is remarkable that brief exposure to DHT could normalize MF transmission given that changes in BDNF synthesis and axonal sprouting take more time. The results raise the possibility that Gdx makes the MF pathway sensitive to acute androgen exposure when it normally is not. One mechanism is that androgen receptors on the cell surface are normally downregulated in the presence of normal testosterone levels. Therefore, addition of more androgen in vitro cannot elicit a detectable effect. This explanation has experimental support: cell surface expression of androgen receptors increases in response to reduced levels of circulating androgens (Kerr et al., 1995; Fargo et al., 2009; Meyer et al., 2009; Hsieh et al., 2011). Alternatively, increased androgen receptor expression at the cell surface of Gdx rats could be a compensatory response to increased excitability.

One cannot rule out the possibility that other metabolites of testosterone in addition to DHT contributed to the effects of Gdx. Regarding the metabolite of DHT that acts on $\mathrm{GABA}_{\mathrm{A}}$ receptors, Adiol, there were no detectable effects under conditions in which DHT exerted a robust influence. However, it is possible that Adiol would have exhibited effects when examined in other experimental paradigms. Regarding metabolites of testosterone that act on estrogen receptors [(17 $\beta$-estradiol and $5 \alpha$ androstane-3 $\beta$, 17 $\beta$-diol (Pak et al., 2004; Handa et al., 2008; Handa et al., 2011)], one cannot rule out effects of these metabolites either. Although some studies suggest that males are relatively insensitive to $17 \beta$-estradiol compared with females, for example, in the number of hippocampal CA1 spine synapses that increase in response to $17 \beta$-estradiol administration (Woolley et al., 1990; Cooke and Woolley, 2005; MacLusky et al., 2006; Woolley, 2007), and other measures of hippocampal function (Huang and Woolley, 2012; Vierk et al., 2012), other studies have shown robust effects of $17 \beta$-estradiol in males (Foy et al., 1999; Mukai et al., 2006; Murakami et al., 2006; Kramar et al., 2009; Mukai et al., 2009; Grassi et al., 2011; Kramar et al., 2012).

It is surprising that acute exposure to Adiol had no effect in slices from sham or Gdx rats because others have found effects, and these are consistent with enhanced GABAergic inhibition, such as inhibition of convulsant-induced seizures in vivo or re- 
duction in epileptiform discharges in vitro (Reddy, 2004a, $2004 b$ ). One possible explanation is that Adiol has more robust effects on seizure activity than normal activity. It is also possible that the high concentrations of Adiol cause direct (agonist) actions at the $\mathrm{GABA}_{\mathrm{A}}$ receptor (Penatti and Henderson, 2009; Reddy, 2010). High concentrations of Adiol may also be effective because Adiol can be converted to DHT.

Increased BDNF expression, Trk dependence of MF transmission and excitability, and MF sprouting after $G d x$

The results are consistent with previous studies in males showing that K252a blocks hyperexcitability induced by exposure of hippocampal slices to BDNF (Scharfman, 1997) and are consistent with excitatory effects of BDNF in males that have been observed in vivo (Gomez-Palacio-Schjetnan and Escobar, 2008; Schjetnan and Escobar, 2010), as well as other subfields: area CA1 (Lu et al., 2008; Minichiello, 2009) and dentate gyrus (Bramham, 2007). In addition, the results are consistent with studies showing that K252a blocked hyperexcitability evoked by MF stimuli in male C57bl6 mice when BDNF was constitutively overexpressed (Croll et al., 1999), and female rats where MF BDNF was elevated (Scharfman et al., 2003, 2007).

The mechanism by which androgen depletion regulates MF BDNF synthesis could be similar to the mechanism proposed for $17 \beta$-estradiol: a direct effect on a putative estrogen response element in the BDNF gene (Sohrabji et al., 1995). Androgen response elements exist (Fargo et al., 2009), but it is not clear whether androgen response elements are present on the BDNF gene. Another potential mechanism is activity-dependent synthesis of BDNF (Isackson et al., 1991; Aid et al., 2007), which has been suggested (Blurton-Jones and Tuszynski, 2006). Because Gdx increases neuronal excitability, it could induce MF BDNF expression by this mechanism.

It is noteworthy that $17 \beta$-estradiol exerts its effects on synaptic plasticity in area CA1 by regulating the cytoskeleton (Kramar et al., 2012). A similar mechanism could be responsible for effects of Gdx (e.g., sprouting), especially in light of the evidence that local estradiol synthesis occurs in the male and exerts effects (Grassi et al., 2011).

\section{Gdx effects on the MF pathway: a presynaptic site of action?}

Increased PPF and PTP in Gdx rats support a presynaptic site of action. This idea is consistent with the evidence that androgen receptors and Trk receptors are present in MF terminals (Tabori et al., 2005). A presynaptic mechanism also could explain increased MF LTP in Gdx rats because an LTP induction protocol was used that is similar to one that induces LTP by a presynaptic mechanism (Kwon and Castillo, 2008). MF sprouting and increased BDNF in MFs of Gdx rats could also contribute to a change in MF transmission that is presynaptic. Notably, BDNF increases transmitter release at other hippocampal synapses (Xu et al., 2000; Tyler et al., 2006) and in prior studies of normal adult males, BDNF appeared to act on presynaptic Trk receptors to increase MF transmission (Scharfman, 1997). However, the dendritic targeting of BDNF (Tongiorgi, 2008), which can trigger critical events in LTP (Bramham, 2007), suggests that postsynaptic sites are also important to consider.

\section{Implications}

The data presented here suggest that the effects of androgens in hippocampus are more complex than previously considered. The impression created by past studies is that gonadal steroids confer hippocampal plasticity, and the response to $\mathrm{Gdx}$ in males and females is at least superficially similar (MacLusky et al., 2006). The data presented here suggest that this is not the case. Although ovariectomy of female rats decreases MF BDNF expression and area CA3 excitability, $17 \beta$-estradiol restores it (Scharfman et al., 2003, 2007). Gdx of male rats has the opposite effect, increasing BDNF levels and excitability.

The results suggest potential mechanisms for the clinical findings that have been reported in patients with androgen deprivation or androgen excess. It has been suggested that low serum androgen levels increase the risk for diseases that involve the hippocampus, such as temporal lobe epilepsy (Herzog, 1991; Harden and MacLusky, 2004, 2005), at least in part because of the loss of Adiol and consequent reduction in GABAergic inhibition (Frye, 2006; Reddy and Jian, 2010). The results of the present study suggest an additional mechanism: loss of androgen increases excitability by androgen receptor- and Trk-dependent mechanisms. The decrease in CA1 spine synapses in males after Gdx, previously reported (MacLusky et al., 2006), may be counterbalanced by rising BDNF, increasing MF transmission, excitability, and plasticity. Even if the increase in CA3 excitability is restricted to the initial weeks after androgen depletion, as was studied here, it appears to initiate long-lasting effects on BDNF synthesis and MF sprouting, and could therefore contribute to the increased incidence of epilepsy with age (Hauser and Hesdorffer, 1990).

The data are also relevant to androgen ablation therapy. The results of the present study suggest a possible explanation for the observation that adverse cognitive effects do not necessarily occur during therapy (Nelson et al., 2008; Alibhai et al., 2010a,b). Function may be partially preserved because of an increase in synaptic transmission and plasticity mediated by BDNF in CA3.

Our results also suggest mechanisms for the adverse effects of androgen abuse in men. Psychiatric disturbances, such as mood disorders or aggressive behavior, are a common adverse effect in males abusing anabolic androgenic steroids (Pope and Katz, 1994). Because low hippocampal BDNF levels are common in depression (Shimizu et al., 2003; Wang et al., 2008), it is possible that high levels of anabolic androgens could exert adverse effects on mood by suppressing hippocampal BDNF expression. Indeed, anabolic androgenic steroids lower BDNF levels in hippocampus and prefrontal cortex of rats, leading to a depressed phenotype (Matrisciano et al., 2012). A similar mechanism could underlie aggressive behavior after abuse of anabolic androgens based on mice with a conditional BDNF deletion (interestingly, it was primarily in the dentate gyrus and area CA3), which show increased aggression (Ito et al., 2011). Furthermore, mice bred for increased aggression have a smaller MF plexus in stratum oriens (Sluyter et al., 1994). Therefore, it is possible that high levels of androgens suppress MF BDNF and reduce the MF plexus, contributing to both depression and aggressive behavior.

\section{References}

Aid T, Kazantseva A, Piirsoo M, Palm K, Timmusk T (2007) Mouse and rat BDNF gene structure and expression revisited. J Neurosci Res 85:525-535. CrossRef Medline

Alibhai SM, Breunis H, Timilshina N, Marzouk S, Stewart D, Tannock I, Naglie G, Tomlinson G, Fleshner N, Krahn M, Warde P, Canning SD (2010a) Impact of androgen-deprivation therapy on cognitive function in men with nonmetastatic prostate cancer. J Clin Oncol 28:5030-5037. CrossRef Medline

Alibhai SM, Mahmoud S, Hussain F, Naglie G, Tannock I, Tomlinson G, Fleshner N, Krahn M, Warde P, Klotz L, Breunis H, Leach M, Canning SD (2010b) Levels of sex hormones have limited effect on cognition in older men with or without prostate cancer. Crit Rev Oncol Hematol 73:167175. CrossRef Medline 
Almeida OP, Flicker L (2003) Testosterone and dementia: too much ado about too little data. J Br Menopause Soc 9:107-110. CrossRef Medline

Al Sweidi S, Sánchez MG, Bourque M, Morissette M, Dluzen D, Di Paolo T (2012) Oestrogen receptors and signalling pathways: implications for neuroprotective effects of sex steroids in Parkinson's disease. J Neuroendocrinol 24:48-61. CrossRef Medline

Ball GF, Auger CJ, Bernard DJ, Charlier TD, Sartor JJ, Riters LV, Balthazart J (2004) Seasonal plasticity in the song control system: multiple brain sites of steroid hormone action and the importance of variation in song behavior. Ann N Y Acad Sci 1016:586-610. CrossRef Medline

Barha CK, Galea LA (2010) Influence of different estrogens on neuroplasticity and cognition in the hippocampus. Biochim Biophys Acta 1800:1056-1067. CrossRef Medline

Barron AM, Pike CJ (2011) Sex hormones, aging, and Alzheimer's disease. Front Biosci (Elite Ed) 4:976-997. CrossRef Medline

Becker JB, Berkely KJ, Geary I, Hampson E, Herman JP, Young E, eds. (2008) Sex differences in the brain: from genes to behavior. Oxford: Oxford UP.

Bender R, Heimrich B, Meyer M, Frotscher M (1998) Hippocampal mossy fiber sprouting is not impaired in brain-derived neurotrophic factordeficient mice. Exp Brain Res 120:399-402. CrossRef Medline

Binder DK, Routbort MJ, Ryan TE, Yancopoulos GD, McNamara JO (1999) Selective inhibition of kindling development by intraventricular administration of trkb receptor body. J Neurosci 19:1424-1436. Medline

Blurton-Jones M, Tuszynski MH (2006) Estradiol-induced modulation of estrogen receptor-beta and GABA within the adult neocortex: a potential transsynaptic mechanism for estrogen modulation of BDNF. J Comp Neurol 499:603-612. CrossRef Medline

Bramham CR (2007) Control of synaptic consolidation in the dentate gyrus: mechanisms, functions, and therapeutic implications. Prog Brain Res 163:453-471. CrossRef Medline

Brown TJ, Sharma M, MacLusky NJ (1995) Localization and measurement of occupied androgen receptors in thaw-mounted rat and human prostate tissue sections by in vitro autoradiography. Steroids 60:239-247. CrossRef Medline

Chakraborty G, Magagna-Poveda A, Parratt C, Umans JG, MacLusky NJ, Scharfman HE (2012) Reduced hippocampal brain-derived neurotrophic factor (BDNF) in neonatal rats after prenatal exposure to propylthiouracil (PTU). Endocrinology 153:1311-1316. CrossRef Medline

Cherrier MM, Matsumoto AM, Amory JK, Asthana S, Bremner W, Peskind ER, Raskind MA, Craft S (2005) Testosterone improves spatial memory in men with Alzheimer disease and mild cognitive impairment. Neurology 64:2063-2068. CrossRef Medline

Chetyrkin SV, Hu J, Gough WH, Dumaual N, Kedishvili NY (2001) Further characterization of human microsomal $3 \alpha$-hydroxysteroid dehydrogenase. Arch Biochem Biophys 386:1-10. CrossRef Medline

Claiborne BJ, Xiang Z, Brown TH (1993) Hippocampal circuitry complicates analysis of long-term potentiation in mossy fiber synapses. Hippocampus 3:115-121. CrossRef Medline

Clancy AN, Bonsall RW, Michael RP (1992) Immunohistochemical labeling of androgen receptors in the brain of rat and monkey. Life Sci 50:409417. CrossRef Medline

Conner JM, Lauterborn JC, Yan Q, Gall CM, Varon S (1997) Distribution of brain-derived neurotrophic factor (BDNF) protein and mRNA in the normal adult rat CNS: evidence for anterograde axonal transport. J Neurosci 17:2295-2313. Medline

Cooke BM, Woolley CS (2005) Gonadal hormone modulation of dendrites in the mammalian CNS. J Neurobiol 64:34-46. CrossRef Medline

Cosgrove KE, Galván EJ, Meriney SD, Barrionuevo G (2010) Area CA3 interneurons receive two spatially segregated mossy fiber inputs. Hippocampus 20:1003-1009. CrossRef Medline

Croll SD, Suri C, Compton DL, Simmons MV, Yancopoulos GD, Lindsay RM, Wiegand SJ, Rudge JS, Scharfman HE (1999) Brain-derived neurotrophic factor transgenic mice exhibit passive avoidance deficits, increased seizure severity and in vitro hyperexcitability in the hippocampus and entorhinal cortex. Neuroscience 93:1491-1506. CrossRef Medline

Derrick BE (2007) Plastic processes in the dentate gyrus: a computational perspective. Prog Brain Res 163:417-451. CrossRef Medline

DonCarlos LL, Garcia-Ovejero D, Sarkey S, Garcia-Segura LM, Azcoitia I (2003) Androgen receptor immunoreactivity in forebrain axons and dendrites in the rat. Endocrinology 144:3632-3638. CrossRef Medline

Driscoll I, Resnick SM (2007) Testosterone and cognition in normal aging and Alzheimer's disease: an update. Curr Alzheimer Res 4:33-45. CrossRef Medline

Drummond ES, Harvey AR, Martins RN (2009) Androgens and Alzheimer's disease. Curr Opin Endocrinol Diabetes Obes 16:254-259. CrossRef Medline

Edinger KL, Frye CA (2004) Testosterone's analgesic, anxiolytic, and cognitiveenhancing effects may be due in part to actions of its $5 \alpha$-reduced metabolites in the hippocampus. Behav Neurosci 118:1352-1364. CrossRef Medline

Edinger KL, Frye CA (2005) Testosterone's anti-anxiety and analgesic effects may be due in part to actions of its $5 \alpha$-reduced metabolites in the hippocampus. Psychoneuroendocrinology 30:418-430. CrossRef Medline

Edinger KL, Frye CA (2007a) Androgens' effects to enhance learning may be mediated in part through actions at estrogen receptor- $\beta$ in the hippocampus. Neurobiol Learn Mem 87:78-85. CrossRef Medline

Edinger KL, Frye CA (2007b) Androgens' performance-enhancing effects in the inhibitory avoidance and water maze tasks may involve actions at intracellular androgen receptors in the dorsal hippocampus. Neurobiol Learn Mem 87:201-208. CrossRef Medline

Edinger KL, Lee B, Frye CA (2004) Mnemonic effects of testosterone and its $5 \alpha$-reduced metabolites in the conditioned fear and inhibitory avoidance tasks. Pharmacol Biochem Behav 78:559-568. CrossRef Medline

Edwards HE, Burnham WM, MacLusky NJ (1999) Testosterone and its metabolites affect afterdischarge thresholds and the development of amygdala kindled seizures. Brain Res 838:151-157. CrossRef Medline

Etgen AM, Pfaff D, eds. (2009) Molecular mechanisms of hormone action. Waltham, MA: Academic.

Fargo KN, Pak TR, Foecking EM, Jones KJ (2009) Molecular biology of androgen action. In: Molecular mechanisms of hormone action on behavior (Etgen A, Pfaff D, eds). Waltham, MA: Academic.

Fester L, Prange-Kiel J, Zhou L, Blittersdorf BV, Böhm J, Jarry H, Schumacher M, Rune GM (2012) Estrogen-regulated synaptogenesis in the hippocampus: sexual dimorphism in vivo but not in vitro. J Steroid Biochem Mol Biol 131:24-29. CrossRef Medline

Foy MR (2011) Ovarian hormones, aging and stress on hippocampal synaptic plasticity. Neurobiol Learn Mem 95:134-144. CrossRef Medline

Foy MR, Xu J, Xie X, Brinton RD, Thompson RF, Berger TW (1999) $17 \beta$ Estradiol enhances NMDA receptor-mediated EPSPs and long-term potentiation. J Neurophysiol 81:925-929. Medline

Frye CA (2006) Role of androgens in epilepsy. Expert Rev Neurother 6:1061-1075. CrossRef Medline

Frye CA, Edinger KL (2004) Testosterone's metabolism in the hippocampus may mediate its anti-anxiety effects in male rats. Pharmacol Biochem Behav 78:473-481. CrossRef Medline

Frye CA, Park D, Tanaka M, Rosellini R, Svare B (2001) The testosterone metabolite and neurosteroid $3 \alpha$-androstanediol may mediate the effects of testosterone on conditioned place preference. Psychoneuroendocrinology 26:731-750. CrossRef Medline

Frye CA, Edinger KL, Seliga AM, Wawrzycki JM (2004) $5 \alpha$-Reduced androgens may have actions in the hippocampus to enhance cognitive performance of male rats. Psychoneuroendocrinology 29:1019-1027. CrossRef Medline

Frye CA, Edinger K, Sumida K (2008) Androgen administration to aged male mice increases anti-anxiety behavior and enhances cognitive performance. Neuropsychopharmacology 33:1049-1061. CrossRef Medline

Frye CA, Edinger KL, Lephart ED, Walf AA (2010) $3 \alpha$-Androstanediol, but not testosterone, attenuates age-related decrements in cognitive, anxiety, and depressive behavior of male rats. Front Aging Neurosci 2:15. CrossRef Medline

Fuller SJ, Tan RS, Martins RN (2007) Androgens in the etiology of Alzheimer's disease in aging men and possible therapeutic interventions. J Alzheimers Dis 12:129-142. Medline

Galea LA (2008) Gonadal hormone modulation of neurogenesis in the dentate gyrus of adult male and female rodents. Brain Res Rev 57:332-341. CrossRef Medline

Gómez-Palacio-Schjetnan A, Escobar ML (2008) In vivo BDNF modulation of adult functional and morphological synaptic plasticity at hippocampal mossy fibers. Neurosci Lett 445:62-67. CrossRef Medline

Gooren L (2003) Testosterone supplementation: why and for whom? Aging Male 6:184-199. CrossRef Medline

Grassi S, Tozzi A, Costa C, Tantucci M, Colcelli E, Scarduzio M, Calabresi P, Pettorossi VE (2011) Neural $17 \beta$-estradiol facilitates long-term poten- 
tiation in the hippocampal CA1 region. Neuroscience 192:67-73. CrossRef Medline

Handa RJ, Pak TR, Kudwa AE, Lund TD, Hinds L (2008) An alternate pathway for androgen regulation of brain function: activation of estrogen receptor $\beta$ by the metabolite of dihydrotestosterone, $5 \alpha$-androstane$3 \beta, 17 \beta$-diol. Horm Behav 53:741-752. CrossRef Medline

Handa RJ, Ogawa S, Wang JM, Herbison AE (2012) Roles for oestrogen receptor $\beta$ in adult brain function. J Neuroendocrinol 24:160-173. CrossRef Medline

Harden C, MacLusky NJ (2004) Aromatase inhibition, testosterone, and seizures. Epilepsy Behav 5:260-263. CrossRef Medline

Harden C, MacLusky NJ (2005) Aromatase inhibitors as add-on treatment for men with epilepsy. Expert Rev Neurother 5:123-127. CrossRef Medline

Harley CW, Malsbury CW, Squires A, Brown RA (2000) Testosterone decreases $\mathrm{CA} 1$ plasticity in vivo in gonadectomized male rats. Hippocampus 10:693-697. CrossRef Medline

Harooni HE, Naghdi N, Sepehri H, Rohani AH (2008) Intrahippocampal injection of testosterone impaired acquisition, consolidation and retrieval of inhibitory avoidance learning and memory in adult male rats. Behav Brain Res 188:71-77. CrossRef Medline

Hatanaka Y, Mukai H, Mitsuhashi K, Hojo Y, Murakami G, Komatsuzaki Y, Sato R, Kawato S (2009) Androgen rapidly increases dendritic thorns of CA3 neurons in male rat hippocampus. Biochem Biophys Res Commun 381:728-732. CrossRef Medline

Hauser WA, Hesdorffer DC (1990) Epilepsy: frequency, causes and consequences. Landover, MD: Epilepsy Foundation of America.

Herzog AG (1991) Reproductive endocrine considerations and hormonal therapy for men with epilepsy. Epilepsia 32[Suppl 6]:S34-S37.

Hsieh JT, Chen SC, Yu HJ, Chang HC (2011) Finasteride upregulates expression of androgen receptor in hyperplastic prostate and lncap cells: implications for chemoprevention of prostate cancer. Prostate 71:1115-1121. CrossRef Medline

Huang GZ, Woolley CS (2012) Estradiol acutely suppresses inhibition in the hippocampus through a sex-specific endocannabinoid and mglurdependent mechanism. Neuron 74:801-808. CrossRef Medline

Isackson PJ, Huntsman MM, Murray KD, Gall CM (1991) BDNF mRNA expression is increased in adult rat forebrain after limbic seizures: temporal patterns of induction distinct from NGF. Neuron 6:937-948. CrossRef Medline

Isgor C, Sengelaub DR (2003) Effects of neonatal gonadal steroids on adult CA3 pyramidal neuron dendritic morphology and spatial memory in rats. J Neurobiol 55:179-190. CrossRef Medline

Ito W, Chehab M, Thakur S, Li J, Morozov A (2011) BDNF-restricted knockout mice as an animal model for aggression. Genes Brain Behav 10:365-374. CrossRef Medline

Jaffe DB, Gutiérrez R (2007) Mossy fiber synaptic transmission: communication from the dentate gyrus to area CA3. Prog Brain Res 163:109-132. CrossRef Medline

Kaminski RM, Marini H, Kim WJ, Rogawski MA (2005) Anticonvulsant activity of androsterone and etiocholanolone. Epilepsia 46:819-827. CrossRef Medline

Kamiya H, Ozawa S, Manabe T (2002) Kainate receptor-dependent shortterm plasticity of presynaptic $\mathrm{Ca}^{2+}$ influx at the hippocampal mossy fiber synapses. J Neurosci 22:9237-9243. Medline

Kang H, Jia LZ, Suh KY, Tang L, Schuman EM (1996) Determinants of BDNF-induced hippocampal synaptic plasticity: role of the trk b receptor and the kinetics of neurotrophin delivery. Learn Mem 3:188-196. CrossRef Medline

Kerr JE, Allore RJ, Beck SG, Handa RJ (1995) Distribution and hormonal regulation of androgen receptor (AR) and AR messenger ribonucleic acid in the rat hippocampus. Endocrinology 136:3213-3221. CrossRef Medline

Kramár EA, Chen LY, Brandon NJ, Rex CS, Liu F, Gall CM, Lynch G (2009) Cytoskeletal changes underlie estrogen's acute effects on synaptic transmission and plasticity. J Neurosci 29:12982-12993. CrossRef Medline

Kramar EA, Babayan AH, Gall CM, Lynch G (2012) Estrogen promotes learning-related plasticity by modifying the synaptic cytoskeleton. Neuroscience. Advance online publication. Retrieved. January 22, 2013. doi: 10.1016/j.neuroscience.2012.10.038. CrossRef

Kwon HB, Castillo PE (2008) Long-term potentiation selectively expressed by NMDA receptors at hippocampal mossy fiber synapses. Neuron 57 : 108-120. CrossRef Medline

Leranth C, Petnehazy O, MacLusky NJ (2003) Gonadal hormones affect spine synaptic density in the CA1 hippocampal subfield of male rats. J Neurosci 23:1588-1592. Medline

Lorente de No R (1934) Studies on the structure of the cerebral cortex: continuation of the study of the ammonic system. J Psychol Neurol 46:113-177.

Louissaint A Jr, Rao S, Leventhal C, Goldman SA (2002) Coordinated interaction of neurogenesis and angiogenesis in the adult songbird brain. Neuron 34:945-960. CrossRef Medline

Lowenstein DH, Arsenault L (1996) Dentate granule cell layer collagen explant cultures: spontaneous axonal growth and induction by brainderived neurotrophic factor or basic fibroblast growth factor. Neuroscience 74:1197-1208. CrossRef Medline

Lu Y, Christian K, Lu B (2008) BDNF: a key regulator for protein synthesisdependent LTP and long-term memory? Neurobiol Learn Mem 89:312323. CrossRef Medline

Luchetti S, Huitinga I, Swaab DF (2011) Neurosteroid and GABA $A_{A}$ receptor alterations in Alzheimer's disease, Parkinson's disease and multiple sclerosis. Neuroscience 191:6-21. CrossRef Medline

MacLusky NJ, Hajszan T, Prange-Kiel J, Leranth C (2006) Androgen modulation of hippocampal synaptic plasticity. Neuroscience 138:957-965. CrossRef Medline

Matousek RH, Sherwin BB (2010) Sex steroid hormones and cognitive functioning in healthy, older men. Horm Behav 57:352-359. CrossRef Medline

Matrisciano F, Modafferi AM, Togna GI, Barone Y, Pinna G, Nicoletti F, Scaccianoce S (2010) Repeated anabolic androgenic steroid treatment causes antidepressant-reversible alterations of the hypothalamicpituitary-adrenal axis, BDNF levels and behavior. Neuropharmacology 58:1078-1084. CrossRef Medline

McEwen BS, Milner TA (2007) Hippocampal formation: Shedding light on the influence of sex and stress on the brain. Brain Res Rev 55:343-355. CrossRef Medline

McLaughlin KJ, Baran SE, Conrad CD (2009) Chronic stress- and sexspecific neuromorphological and functional changes in limbic structures. Mol Neurobiol 40:166-182. CrossRef Medline

Meyer RP, Gehlhaus M, Schwab R, Bürck C, Knoth R, Hagemeyer CE (2009) Concordant up-regulation of cytochrome P450 Cyp3a11, testosterone oxidation and androgen receptor expression in mouse brain after xenobiotic treatment. J Neurochem 109:670-681. CrossRef Medline

Minichiello L (2009) Trkb signalling pathways in LTP and learning. Nat Rev Neurosci 10:850-860. CrossRef Medline

Mitsushima D (2011) Sex differences in the septo-hippocampal cholinergic system in rats: behavioral consequences. Curr Top Behav Neurosci 8:57-71. CrossRef Medline

Mitsushima D, Takase K, Takahashi T, Kimura F (2009) Activational and organisational effects of gonadal steroids on sex-specific acetylcholine release in the dorsal hippocampus. J Neuroendocrinol 21:400-405. CrossRef Medline

Mizoguchi K, Kunishita T, Chui DH, Tabira T (1992) Stress induces neuronal death in the hippocampus of castrated rats. Neurosci Lett 138:157160. CrossRef Medline

Mukai H, Tsurugizawa T, Ogiue-Ikeda M, Murakami G, Hojo Y, Ishii H, Kimoto T, Kawato S (2006) Local neurosteroid production in the hippocampus: influence on synaptic plasticity of memory. Neuroendocrinology 84:255-263. CrossRef Medline

Mukai H, Kimoto T, Hojo Y, Kawato S, Murakami G, Higo S, Hatanaka Y, Ogiue-Ikeda M (2010) Modulation of synaptic plasticity by brain estrogen in the hippocampus. Biochim Biophys Acta 1800:1030-1044. CrossRef Medline

Murakami G, Tsurugizawa T, Hatanaka Y, Komatsuzaki Y, Tanabe N, Mukai H, Hojo Y, Kominami S, Yamazaki T, Kimoto T, Kawato S (2006) Comparison between basal and apical dendritic spines in estrogen-induced rapid spinogenesis of $\mathrm{CA} 1$ principal neurons in the adult hippocampus. Biochem Biophys Res Commun 351:553-558. CrossRef Medline

Naghdi N, Asadollahi A (2004) Genomic and nongenomic effects of intrahippocampal microinjection of testosterone on long-term memory in male adult rats. Behav Brain Res 153:1-6. CrossRef Medline

Naghdi N, Majlessi N, Bozorgmehr T (2005) The effect of intrahippocampal injection of testosterone enanthate (an androgen receptor agonist) and 
anisomycin (protein synthesis inhibitor) on spatial learning and memory in adult, male rats. Behav Brain Res 156:263-268. CrossRef Medline

Nelson CJ, Lee JS, Gamboa MC, Roth AJ (2008) Cognitive effects of hormone therapy in men with prostate cancer: a review. Cancer 113:10971106. CrossRef Medline

Ottem EN, Beck LA, Jordan CL, Breedlove SM (2007) Androgen-dependent regulation of brain-derived neurotrophic factor and tyrosine kinase B in the sexually dimorphic spinal nucleus of the bulbocavernosus. Endocrinology 148:3655-3665. CrossRef Medline

Pak TR, Chung WC, Lund TD, Hinds LR, Clay CM, Handa RJ (2005) The androgen metabolite, $5 \alpha$-androstane- $3 \beta, 17 \beta$-diol ( $3 \beta$ adiol), is a potent modulator of estrogen receptor- $\beta 1$-mediated gene transcription in neuronal cells. Endocrinology 146:147-155. CrossRef Medline

Penatti CAA, Henderson LP (2009) Androgen actions on receptors and channels: regulation of electrical excitability and synaptic transmission. In: Molecular mechanisms of hormone action on behavior (Etgen A, Pfaff D, eds), pp 153-182. Waltham, MA: Academic.

Pierce JP, Kurucz OS, Milner TA (1999) Morphometry of a peptidergic transmitter system: dynorphin b-like immunoreactivity in the rat hippocampal mossy fiber pathway before and after seizures. Hippocampus 9:255-276. CrossRef Medline

Pope HG Jr, Katz DL (1994) Psychiatric and medical effects of anabolicandrogenic steroid use: a controlled study of 160 athletes. Arch Gen Psychiatry 51:375-382. CrossRef Medline

Qiao X, Suri C, Knusel B, Noebels JL (2001) Absence of hippocampal mossy fiber sprouting in transgenic mice overexpressing brain-derived neurotrophic factor. J Neurosci Res 64:268-276. CrossRef Medline

Reddy DS (2004a) Anticonvulsant activity of the testosterone-derived neurosteroid $3 \alpha$-androstanediol. Neuroreport 15:515-518. CrossRef Medline

Reddy DS (2004b) Testosterone modulation of seizure susceptibility is mediated by neurosteroids $3 \alpha$-androstanediol and $17 \beta$-estradiol. Neuroscience 129:195-207. CrossRef Medline

Reddy DS (2010) Neurosteroids: endogenous role in the human brain and therapeutic potentials. Prog Brain Res 186:113-137. CrossRef Medline

Reddy DS, Jian K (2010) The testosterone-derived neurosteroid androstanediol is a positive allosteric modulator of $\mathrm{GABA}_{\mathrm{A}}$ receptors. J Pharmacol Exp Ther 334:1031-1041. CrossRef Medline

Sakata K, Tokue A, Kawai N (2000) Altered synaptic transmission in the hippocampus of the castrated male mouse is reversed by testosterone replacement. J Urol 163:1333-1338. CrossRef Medline

Salin PA, Scanziani M, Malenka RC, Nicoll RA (1996) Distinct short-term plasticity at two excitatory synapses in the hippocampus. Proc Natl Acad Sci U S A 93:13304-13309. CrossRef Medline

Sarkey S, Azcoitia I, Garcia-Segura LM, Garcia-Ovejero D, DonCarlos LL (2008) Classical androgen receptors in nonclassical sites in the brain. Horm Behav 53:753-764. CrossRef Medline

Scharfman HE (1997) Hyperexcitability in combined entorhinal/hippocampal slices of adult rat after exposure to brain-derived neurotrophic factor. J Neurophysiol 78:1082-1095. Medline

Scharfman HE (2007) The CA3 "backprojection" to the dentate gyrus. Prog Brain Res 163:627-637. CrossRef Medline

Scharfman HE, Goodman JH, Sollas AL (2000) Granule-like neurons at the hilar/CA3 border after status epilepticus and their synchrony with area CA3 pyramidal cells: functional implications of seizure-induced neurogenesis. J Neurosci 20:6144-6158. Medline

Scharfman HE, Smith KL, Goodman JH, Sollas AL (2001) Survival of dentate hilar mossy cells after pilocarpine-induced seizures and their synchronized burst discharges with area CA3 pyramidal cells. Neuroscience 104:741-759. CrossRef Medline

Scharfman HE, Sollas AL, Smith KL, Jackson MB, Goodman JH (2002) Structural and functional asymmetry in the normal and epileptic rat dentate gyrus. J Comp Neurol 454:424-439. CrossRef Medline

Scharfman HE, Mercurio TC, Goodman JH, Wilson MA, MacLusky NJ (2003) Hippocampal excitability increases during the estrous cycle in the rat: a potential role for brain-derived neurotrophic factor. J Neurosci 23:11641-11652. Medline

Scharfman HE, Hintz TM, Gomez J, Stormes KA, Barouk S, MalthankarPhatak GH, McCloskey DP, Luine VN, MacLusky NJ (2007) Changes in hippocampal function of ovariectomized rats after sequential low doses of estradiol to simulate the preovulatory estrogen surge. Eur J Neurosci 26:2595-2612. CrossRef Medline
Schjetnan AG, Escobar ML (2012) In vivo BDNF modulation of hippocampal mossy fiber plasticity induced by high frequency stimulation. Hippocampus 22:1-8. CrossRef Medline

Scott R, Lalic T, Kullmann DM, Capogna M, Rusakov DA (2008) Target-cell specificity of kainate autoreceptor and $\mathrm{Ca}^{2+}$-store-dependent short-term plasticity at hippocampal mossy fiber synapses. J Neurosci 28:1313913149. CrossRef Medline

Shetty AK, Zaman V, Shetty GA (2003) Hippocampal neurotrophin levels in a kainate model of temporal lobe epilepsy: a lack of correlation between brain-derived neurotrophic factor content and progression of aberrant dentate mossy fiber sprouting. J Neurochem 87:147-159. CrossRef Medline

Shimizu E, Hashimoto K, Okamura N, Koike K, Komatsu N, Kumakiri C, Nakazato M, Watanabe H, Shinoda N, Okada S, Iyo M (2003) Alterations of serum levels of brain-derived neurotrophic factor (BDNF) in depressed patients with or without antidepressants. Biol Psychiatry 54:70-75. CrossRef Medline

Skucas VA, Mathews IB, Yang J, Cheng Q, Treister A, Duffy AM, Verkman AS, Hempstead BL, Wood MA, Binder DK, Scharfman HE (2011) Impairment of select forms of spatial memory and neurotrophin-dependent synaptic plasticity by deletion of glial aquaporin-4. J Neurosci 31:6392-6397. CrossRef Medline

Sluyter F, Jamot L, van Oortmerssen GA, Crusio WE (1994) Hippocampal mossy fiber distributions in mice selected for aggression. Brain Res 646: 145-148. CrossRef Medline

Smith CC, Vedder LC, McMahon LL (2009) Estradiol and the relationship between dendritic spines, NR2b containing NMDA receptors, and the magnitude of long-term potentiation at hippocampal CA3-CA1 synapses. Psychoneuroendocrinology 34 [Suppl 1]:S130-S142.

Smith MD, Jones LS, Wilson MA (2002) Sex differences in hippocampal slice excitability: role of testosterone. Neuroscience 109:517-530. CrossRef Medline

Sohrabji F, Miranda RC, Toran-Allerand CD (1995) Identification of a putative estrogen response element in the gene encoding brain-derived neurotrophic factor. Proc Natl Acad Sci U S A 92:11110-11114. CrossRef Medline

Spencer JL, Waters EM, Romeo RD, Wood GE, Milner TA, McEwen BS (2008) Uncovering the mechanisms of estrogen effects on hippocampal function. Front Neuroendocrinol 29:219-237. CrossRef Medline

Stevens SJ, Harden CL (2011) Hormonal therapy for epilepsy. Curr Neurol Neurosci Rep 11:435-442. CrossRef Medline

Tabori NE, Stewart LS, Znamensky V, Romeo RD, Alves SE, McEwen BS, Milner TA (2005) Ultrastructural evidence that androgen receptors are located at extranuclear sites in the rat hippocampal formation. Neuroscience 130:151-163. CrossRef Medline

Tamura M, Koyama R, Ikegaya Y, Matsuki N, Yamada MK (2006) K252a, an inhibitor of trk, disturbs pathfinding of hippocampal mossy fibers. Neuroreport 17:481-486. CrossRef Medline

Tamura M, Tamura N, Ikeda T, Koyama R, Ikegaya Y, Matsuki N, Yamada MK (2009) Influence of brain-derived neurotrophic factor on pathfinding of dentate granule cell axons, the hippocampal mossy fibers. Mol Brain 2:2. CrossRef Medline

Tongiorgi E (2008) Activity-dependent expression of brain-derived neurotrophic factor in dendrites: facts and open questions. Neurosci Res 61:335-346. CrossRef Medline

Toran-Allerand CD (1996) Mechanisms of estrogen action during neural development: mediation by interactions with the neurotrophins and their receptors? J Steroid Biochem Mol Biol 56:169-178. CrossRef Medline

Toran-Allerand CD, Miranda RC, Bentham WD, Sohrabji F, Brown TJ, Hochberg RB, MacLusky NJ (1992) Estrogen receptors colocalize with low-affinity nerve growth factor receptors in cholinergic neurons of the basal forebrain. Proc Natl Acad Sci U S A 89:4668-4672. CrossRef

Tyler WJ, Zhang XL, Hartman K, Winterer J, Muller W, Stanton PK, PozzoMiller L (2006) BDNF increases release probability and the size of a rapidly recycling vesicle pool within rat hippocampal excitatory synapses. J Physiol 574:787-803. CrossRef Medline

Verhovshek T, Cai Y, Osborne MC, Sengelaub DR (2010) Androgen regulates brain-derived neurotrophic factor in spinal motoneurons and their target musculature. Endocrinology 151:253-261. CrossRef Medline

Vierk R, Glassmeier G, Zhou L, Brandt N, Fester L, Dudzinski D, Wilkars W, Bender RA, Lewerenz M, Gloger S, Graser L, Schwarz J, Rune GM (2012) 
Aromatase inhibition abolishes LTP generation in female but not in male mice. J Neurosci 32:8116-8126. CrossRef Medline

Wang JW, Dranovsky A, Hen R (2008) The when and where of BDNF and the antidepressant response. Biol Psychiatry 63:640-641. CrossRef Medline

Wissman AM, Brenowitz EA (2009) The role of neurotrophins in the seasonal-like growth of the avian song control system. J Neurosci 29: 6461-6471. CrossRef Medline

Wójtowicz T, Mozrzymas JW (2010) Estradiol and GABAergic transmission in the hippocampus. Vitam Horm 82:279-300. CrossRef Medline

Woolley CS (2007) Acute effects of estrogen on neuronal physiology. Annu Rev Pharmacol Toxicol 47:657-680. CrossRef Medline

Woolley CS, Gould E, Frankfurt M, McEwen BS (1990) Naturally occurring fluctuation in dendritic spine density on adult hippocampal pyramidal neurons. J Neurosci 10:4035-4039. Medline

Xu B, Gottschalk W, Chow A, Wilson RI, Schnell E, Zang K, Wang D, Nicoll
RA, Lu B, Reichardt LF (2000) The role of brain-derived neurotrophic factor receptors in the mature hippocampus: modulation of long-term potentiation through a presynaptic mechanism involving trkb. J Neurosci 20:6888-6897. Medline

Yan Q, Rosenfeld RD, Matheson CR, Hawkins N, Lopez OT, Bennett L, Welcher AA (1997) Expression of brain-derived neurotrophic factor protein in the adult rat central nervous system. Neuroscience 78:431-448. CrossRef Medline

Yeap BB (2009) Testosterone and ill-health in aging men. Nat Clin Pract Endocrinol Metab 5:113-121. CrossRef Medline

Yoshino M, Sawada S, Yamamoto C, Kamiya H (1996) A metabotropic glutamate receptor agonist DCG-IV suppresses synaptic transmission at mossy fiber pathway of the guinea pig hippocampus. Neurosci Lett 207:70-72. CrossRef Medline

Zivin JA, Bartko JJ (1976) Statistics for disinterested scientists. New York: Life Sciences. 